\title{
Entre pétrole et tourisme, la conservation participative des patrimoines locaux au Timor- Leste (Timor oriental)
}

Exemple de Suai et Ataúro (districts de Covalima et Dili)

Between oil and tourism, the participative conservation of local heritage in East

Timor. Example from Suai and Ataúro (districts of Covalima and Dili)

Dominique Guillaud, Laure Emperaire, Brunna Crespi, Rosalia Soares, Amandine Pequignot et Jean-Christophe Galipaud

\section{(2) OpenEdition}

\section{Édition électronique}

URL : http://journals.openedition.org/ethnoecologie/2947

DOI : $10.4000 /$ ethnoecologie.2947

ISSN : 2267-2419

\section{Éditeur}

Laboratoire Eco-anthropologie et Ethnobiologie

\section{Référence électronique}

Dominique Guillaud, Laure Emperaire, Brunna Crespi, Rosalia Soares, Amandine Pequignot et JeanChristophe Galipaud, « Entre pétrole et tourisme, la conservation participative des patrimoines locaux au Timor-Leste (Timor oriental) », Revue d'ethnoécologie [En ligne], 11 | 2017, mis en ligne le 03 juillet 2017, consulté le 21 avril 2019. URL : http://journals.openedition.org/ethnoecologie/2947 ; DOI : 10.4000/ethnoecologie.2947

Ce document a été généré automatiquement le 21 avril 2019

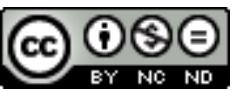

Revue d'ethnoécologie est mis à disposition selon les termes de la licence Creative Commons Attribution - Pas d'Utilisation Commerciale - Pas de Modification 4.0 International. 


\section{Entre pétrole et tourisme, la conservation participative des patrimoines locaux au Timor-Leste (Timor oriental)}

Exemple de Suai et Ataúro (districts de Covalima et Dili)

Between oil and tourism, the participative conservation of local heritage in East

Timor. Example from Suai and Ataúro (districts of Covalima and Dili)

Dominique Guillaud, Laure Emperaire, Brunna Crespi, Rosalia Soares, Amandine Pequignot et Jean-Christophe Galipaud

\section{Introduction}

1 Le Timor-Leste est un jeune pays en construction, porteur d'une riche diversité culturelle qui s'exprime dans les 34 langues parlées sur tout le territoire. Si le gouvernement a inscrit dans sa constitution la reconnaissance des normes et coutumes locales comme un élément à protéger et à valoriser, aucun statut particulier n'est accordé aux différents groupes culturels qui composent la nation. Dans une politique culturelle très top-down, les projets sont décidés dans les Ministères ou par les experts étrangers et ne prennent guère en compte les demandes des populations locales. Notre insertion dans l'une des instances en charge des politiques culturelles et du patrimoine, le Secrétariat d'État à l'Art et à la Culture, nous a amenés à réfléchir à la manière dont il était possible de prendre en compte les patrimoines des communautés locales dans un contexte marqué par un fort investissement dans des projets de développement lourds (infrastructures, tourisme, modernisation agricole, etc.).

2 Le patrimoine, dans l'acception que notre équipe en a développé depuis plus d'une décennie $^{1}$, ne se focalise pas sur des objets déterminés mais se discerne par une série de critères accompagnant le processus de construction patrimoniale : collectif, hérité d'un 
passé réel ou recomposé, investi d'une charge sociale, symbolique ou affective, il est géré selon des règles d'usage, d'accès, de conservation qui en assurent la transmission sous une forme continuellement actualisée, rarement à l'identique, au vu des dynamiques sociales, culturelles, politiques, environnementales dans lequel il s'ancre (Cormier-Salem \& Guillaud 2016 : 257). La référence au temps long et à un principe de gestion vertueuse en vue d'une transmission aux générations à venir en font un paradigme intéressant pour les politiques publiques. De plus, il ne s'agit pas ici d'un patrimoine mis en scène par les institutions nationales ou internationales, comme le sont les maisons sacrées et éléments architecturaux coloniaux, les textiles, les danses, etc., qui font régulièrement l'objet d'expositions ou de mesures de conservation, mais d'un patrimoine dont les populations locales sont dépositaires selon les principes énoncés ci-dessus.

3 Non inclus dans les catégories patrimoniales des institutions gouvernementales, et souvent pas même désignés comme tels, ces patrimoines locaux sont aujourd'hui pris entre deux dynamiques contradictoires. D'un côté, ils sont menacés par l'aspiration quasiunanime de la société à la modernité, qui mène à des mobilités et à des déracinements préjudiciables aux relations des sociétés locales avec les lieux et les territoires où s'enracinent la quasi-totalité des patrimoines locaux. D'un autre côté, ils sont très sollicités en réaction à cette même modernité, qui conduit les groupes locaux à renforcer leurs repères identitaires, et sont même de plus en plus mobilisés par les populations comme par le gouvernement depuis l'indépendance, en réaction à la politique d'éradication culturelle menée durant l'occupation indonésienne.

4 L'objectif général de notre approche est ainsi de renseigner les thèmes et objets importants du patrimoine des populations locales et leurs fonctionnements dans la perspective d'en faire des atouts dans un développement plus acceptable pour les populations locales. Cette perspective oblige à une réflexion théorique, appliquée et éthique sur les liens entre recherche, société et développement. L'outil que nous avons choisi pour favoriser à la fois cette interlocution et cette reconnaissance est celui du collaboratif, mis en pratique dans le but de recueillir les représentations par ces populations de ce qui « fait » pour eux patrimoine, afin de le faire reconnaître comme tel avec leur validation et leur accord, ce dans un contexte qui n'est pour le moment que peu ouvert à ces questions.

5 Cette étude s'appuie sur deux terrains, Suai et Ataúro (Figure 1) situés dans des contextes naturels et économiques différents, qui illustrent les deux principales options de développement du pays, le sud pétrolier et le nord voué au tourisme. Elle nous permet de décliner, à partir de ces deux exemples, les différentes modalités que peut prendre cette méthode collaborative. 
Figure 1 : Le Timor-Leste et les deux terrains de l'étude

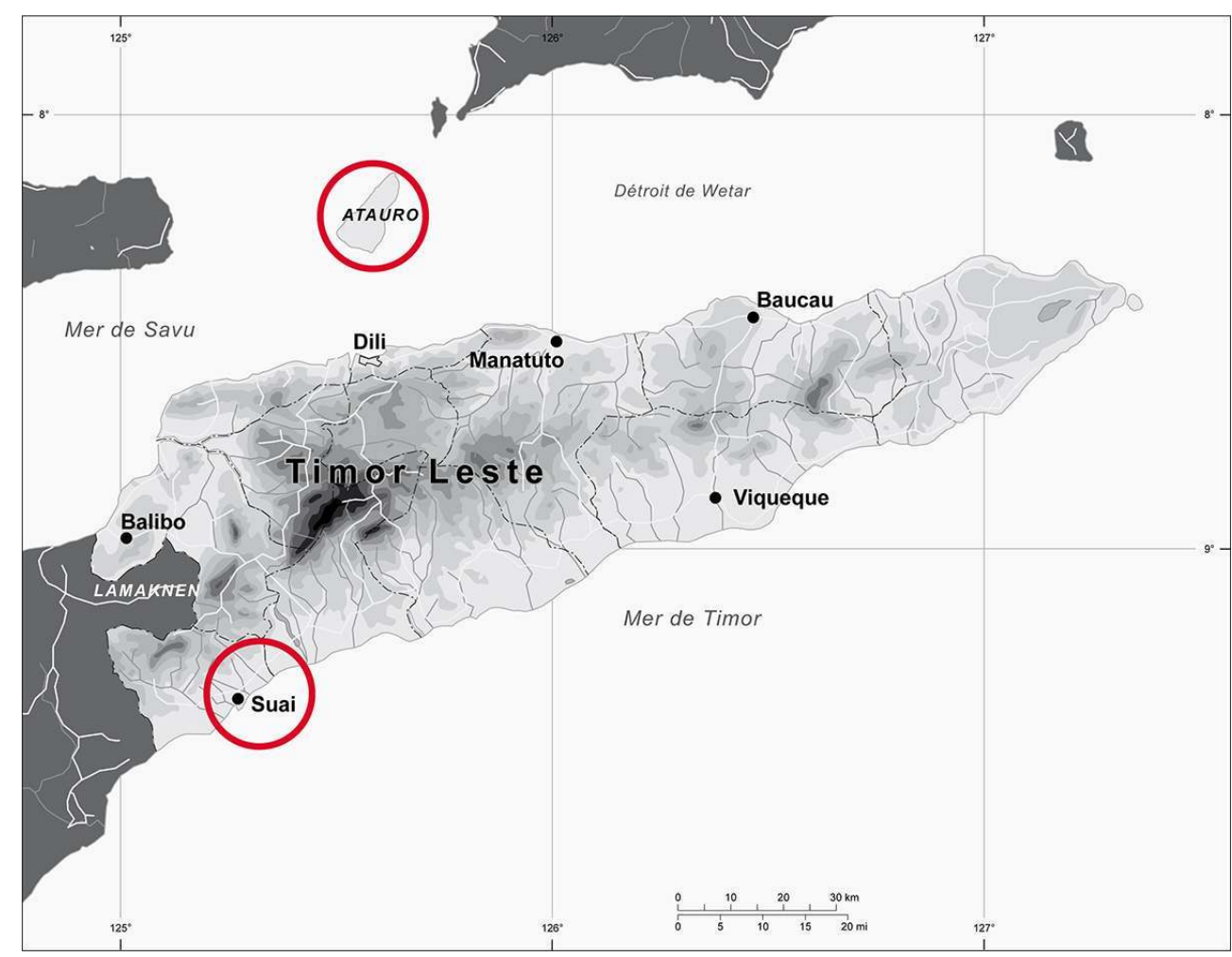

(c) L. Billault

\section{Le contexte timorais}

\section{La société locale}

Les sociétés sont organisées en maisons (uma en tetun) qui, pour simplifier, désignent un bâtiment et une unité lignagère portant le même nom ${ }^{2}$. Chaque maison est engagée dans de multiples relations d'alliance et de préséance avec d'autres maisons, l'ensemble formant, dans un lieu donné qu'on nommera par commodité le village, une combinaison hiérarchisée, de la plus noble ou haute maison, à la simple maison roturière. Des scissions des membres d'une maison et leur départ peuvent donner naissance, ailleurs, à une autre maison portant le même nom, aboutissant à des « lignées de maisons » qui se réfèrent à l'unité et au lieu d'origine. D'autres scissions peuvent aboutir à la création de maisons prenant un nouveau nom, avec une certaine mémoire des origines. Au fil des scissions et des déplacements, les maisons se recomposent dans des lieux nouveaux, aboutissant à des combinaisons uniques pour chacun des établissements.

7 Les populations du Timor Leste sont rurales à $80 \%$, l'agriculture dite traditionnelle est prédominante, et il s'y discerne l'agrégation de plusieurs systèmes de culture. L'un est basé sur l'exploitation de plantes spontanées ou semi-spontanées, en particulier les palmiers Corypha utan dont on extrait un sagou, et Borassus flabellifer dont on tire du vin. Un autre système s'appuie sur la culture de tubercules, ignames et taros, et plus récemment manioc. Le plus visible enfin est basé sur la céréaliculture. Plusieurs espèces (millet Setaria italica, Coix lacrima jobi, sorgho Sorghum bicolor, et aujourd'hui maïs Zea mays 
) semblent avoir joué un rôle central (Guillaud 2015). Ce bref panorama des agricultures laisse entrevoir un brassage important des systèmes de plantes ${ }^{3}$ et aussi des peuplements qui les ont véhiculées. Ce point a son importance car la préséance des arrivées conditionne en grande partie la territorialité des sociétés. Friedberg résume cette situation dans le Haut-Lamaknen : « les Bunaq ne se considèrent pas comme les véritables maîtres du sol. Leurs ancêtres mythiques sont venus d'ailleurs, peut-être d'au-delà des mers, abordant Timor par l'est et le sud. Quand ils sont arrivés sur l'actuel territoire de Lamaknen, celui-ci était occupé par une population qu'ils considèrent comme les véritables maîtres du sol et qu'ils appellent du terme général de Melus. [...] Les Bunaq ont tué ou chassé les Melus pour occuper leur territoire » (Friedberg 1971: 490). Le territoire est perçu comme contrôlé par diverses puissances, celles des premiers occupants dont les esprits contrôlent toujours le sol, celles des ancêtres qui ont édicté les principes que les vivants doivent respecter, et aussi celle des âmes des végétaux qui peuvent s'affaiblir et pénaliser les récoltes, celle des esprits gardiens de la terre, de l'eau, des forêts (Friedberg 1971 : 520, Friedberg 2014, Hicks 1996, Kehi \& Palmer 2012: 451, etc.). Les groupes ont développé avec ces non-humains omniprésents et multiformes des relations visant à garantir une bonne entente, à travers un système de rituels à différentes échelles, du champ ou de la maison au territoire du groupe tout entier. Les rituels se centrent sur des lieux et objets forts, investis par les non-humains, qui balisent le territoire : anciens sites d'habitat, forêts sacrées, tombes, arbres symboliques comme le banian, grottes et abris sous roche, rochers remarquables, murets... L'espace rituel dessine ainsi les limites territoriales de la communauté. La plupart des rituels et cérémonies coutumières sont liées aux pluies, à la fructification et à la récolte des céréales, et jadis à la guerre. Friedberg (1971 : 523), livrant la liste impressionnante de ceux qu'elle a observés chez les Bunaq, remarque cependant qu'ils sont surtout « destinés à réaffirmer les liens sociaux et politiques entre ceux qui les accomplissent, mais que très peu ont pour but d'agir directement sur les plantes ou la production ».

Les grandes religions parvenues avec les colonisations néerlandaise et portugaise dans la région ont eu des effets distincts sur les pratiques rituelles. Dans les régions soumises à une évangélisation protestante, comme une bonne partie d'Ataúro, les récits anciens, s'ils sont encore dans les mémoires, ont été plus ou moins censurés, et les rituels réinvestis dans les événements du calendrier chrétien ou mis au service de l'Église. L'évangélisation catholique, qui concerne la majeure partie du Timor-Leste, a pour sa part très largement permis le maintien de ces pratiques. Elles jouent au regard du patrimoine un rôle essentiel qui sera précisé ci-après.

9 Au moins depuis la fin du $\mathrm{XIX}^{\mathrm{e}}$ siècle, l'économie se caractérise par la coexistence fonctionnelle d'un secteur traditionnel et d'un secteur plus moderne, se situant dans le contexte de l'économie duelle décrite par Julius Boeke (1953). Les cultures «riches» (destinées à être vendues et dotées d'une valeur marchande importante, comme le café) s'opposent aux cultures "pauvres » (destinées à la subsistance et aux échanges locaux, avec peu de valeur marchande), qui au Timor-Leste ne définissent pas des classes de paysans, mais s'organisent partout en un continuum où, à côté du vivrier, tous développent à des degrés divers des cultures de rente ou la vente d'éventuels surplus. 


\section{La reconstruction et ses acteurs}

10 En 1975, à la colonisation portugaise succède la mainmise indonésienne qui se traduit par les exactions de l'armée combinée à une politique d'éradication des cultures locales. La plupart des éléments de la société traditionnelle sont bouleversés : maisons détruites et populations déplacées, changement des pratiques agraires et des cultures, abandon forcé de la plupart des rituels, destruction de l'environnement ${ }^{4}$. En 1999, la situation est telle qu'elle inspire à l'UNTAET (qui, à partir de 1999, a mandat sur le Timor-Leste), l'image d'une tabula rasa (Chopra 2002) où plus aucune institution ne subsiste. C'est pour l'ONU et ses agences l'occasion de conjurer les expériences désastreuses de ses missions précédentes en Afghanistan et en Somalie en mettant en place et contrôlant, sans pouvoir local concurrent, les structures d'un futur gouvernement. Mais la disparition des structures étatiques était loin de signifier la déshérence des institutions coutumières des zones rurales. Largement marginalisées dans la mise en place de la gouvernance du pays, ces institutions locales sont aujourd'hui encore absentes des instances de décision, même si elles sont largement mobilisées dans un registre symbolique à l'occasion de célébrations nationales. La diversité culturelle et linguistique du pays n'aide guère à mettre en avant ces groupes culturels, et la question de la langue est compliquée par la présence de deux langues officielles (le tetun prasa et le portugais) et de deux langues de travail (l'indonésien et l'anglais).

11 La découverte de pétrole dès les années soixante sur la côte sud ne donna lieu qu'à une exploitation limitée, mais le potentiel estimé était important (Durand 2002 : 106), facteur qui a été décisif dans l'invasion du pays en $1975^{5}$. Aujourd'hui le pétrole timorais est exploité sous la supervision de l'Australie qui reverse un pourcentage des revenus au Timor-Leste. La reconstruction du pays s'est appuyée dès l'indépendance sur cette rente quasi-unique du pétrole et du gaz, qui fournissent 80 à $90 \%$ des revenus de l'État et sont tenus comme les garants d'une indépendance du pays. Toutefois cette indépendance est soumise à beaucoup de conditions : l'ampleur des réserves de gaz et pétrole, la capacité du Timor-Leste à organiser les équipements pour l'exploiter, les relations géostratégiques avec les pays voisins, etc. Les réserves pétrolières sont estimées à 15-25 années d'exploitation, autant dont dispose le pays pour organiser son économie. Pour réduire l'incertitude pétrolière et contrôler a minima les conditions de la production, l'État a opté en 2010 pour un mégaprojet d'infrastructures destinées à traiter le gaz et le pétrole provenant de ses champs d'hydrocarbures. L'idée de base était non seulement de garantir un approvisionnement direct au pays et un produit plus fini, susceptible d'accroître les revenus de cette industrie, mais aussi de créer des emplois dans les secteurs d'activités liés au pétrole et au gaz, et aussi dans les chantiers gigantesques qui étaient planifiés. C'est ainsi qu'est né le projet Tasi Mane sur le littoral sud du pays.

Les autres possibilités de développement étant par ailleurs réduites (Scheiner 2015), le gouvernement a misé, dès son indépendance, sur le tourisme comme un des leviers de développement du pays. Il a mis l'accent sur la nécessité de développer un tourisme durable, appuyé sur les ressources naturelles et culturelles du pays, et développé par les communautés locales pour leur bénéfice : une croissance "économique et culturelle " (Cabasset-Semedo \& Durand 2009 : 216). Toutefois, dans sa mise en œuvre, la dimension locale a été occultée au profit d'une vision générique des activités touristiques comme génératrices d'emplois et d'investissements (p. 217). Sous l'étiquette du tourisme 
s'opposent des perspectives qui vont d'un éco-tourisme aux infrastructures légères, comme celui qui opère aujourd'hui à Ataúro avec le soutien de quelques ONG, à un tourisme de type balnéaire qui demande de fortes capacités d'investissement (CabassetSemedo 2007, La'o Hamutuk 2014), et auquel cette même île est promise.

Les acteurs de ce développement basé sur le pétrole et le tourisme relèvent en théorie des administrations du pays, qui jusqu'à fin $2013^{6}$ étaient secondées par les conseillers et structures des Nations-Unies. Des acteurs privés sont de plus en plus présents, notamment Chinois et Indonésiens qui s'investissent dans le développement des infrastructures et du secteur productif. Comme beaucoup de pays sortant d'une phase de destruction avec l'aide des Nations-Unies, le Timor-Leste connaît une prolifération d'ONG locales et internationales, spécialisées dans les champs les plus divers, et qui prennent en charge des pans entiers de la reconstruction nationale.

Comme on l'a vu, les politiques publiques sont mises en œuvre à l'échelle locale avec une vision déconnectée des fonctionnements locaux. Les postes dans l'administration sont souvent des positions de clientèle, les ministères sont des fiefs de personnalités politiques et les salaires sont bas $^{7}$. Les personnels des ministères ont pour beaucoup été formés en Indonésie ${ }^{8}$, et déploient souvent une vision technocratique du développement où les populations locales sont considérées comme rétrogrades.

Même si cette vision n'est pas prédominante chez notre partenaire, le Secrétariat d'État à l'Art et à la Culture (SEAC) ${ }^{9}$, les opérations prioritaires que celui-ci déploie relèvent de cette vision régalienne sur la culture et les patrimoines. Le SEAC est chargé du montage et du suivi des dossiers des grandes conventions internationales (UNESCO); il est aussi impliqué, dans chacun des 13 districts du Timor Leste, dans la mise en place de centres culturels régionaux visant à soutenir la construction de l'identité nationale. Le SEAC a pour mission de réaliser des inventaires dans un but de préservation et de valorisation (fouilles archéologiques, bases de données, expositions...).

16 Le contexte juridique de cette phase de reconstruction, pour le domaine culturel, est encore très peu structuré. Le Parlement a approuvé en juin 2015 la ratification des trois conventions de l'Unesco (Protection du Patrimoine Mondial, Culturel et Naturel de 1972; Sauvegarde du Patrimoine Culturel Immatériel de 2003; Protection et Promotion de la Diversité des Expressions Culturelles de 2005). Un décret-loi sur le régime juridique du patrimoine culturel de Timor-Leste est en phase d'approbation. La CDB n'a pas été signée par le pays et la conservation de la biodiversité n'est conçue qu'à travers l'établissement d'aires protégées, comme dans l'est du pays celle du parc Nino Konis Santana. Le pays est donc à un moment clé de la construction de ses politiques culturelles et patrimoniales.

\section{Pétrole et développement : le cas de Suai}

\section{Le projet Tasi Mane dans la région de Suai}

17 Le sud du Timor Leste est une région restée jusqu'ici plus ou moins à l'écart du développement, si l'on excepte l'introduction de techniques de mécanisation dans le domaine agricole et les opérations de transmigration menées par les Indonésiens dans les années quatre-vingt. Le district de Covalima $\left(1230 \mathrm{~km}^{2}\right)$ abrite la petite ville de Suai près de laquelle sont prévus les aménagements pétroliers. 

Timor Gap, prévoit l'aménagement du corridor d'infrastructures de Tasi Mane le long de la côte sud-ouest, basé sur les trois pôles de Beaso (traitement du gaz), Betano (raffinerie) et Suai (industries pétrolières et stockage), reliés entre eux par une autoroute. Le projet comporte des zones d'ombre, dont l'ONG locale de veille sur le développement La'o Hamutuk s'est faite de façon infatigable l'écho depuis 2011: le coût total aurait été multiplié par 14 depuis les débuts du projet, et les responsables de celui-ci restent très évasifs sur les retombées locales pour l'emploi, sur l'impact foncier, les déplacements de population prévus et les revenus escomptés de l'aménagement (La'o Hamutuk 2016). Cryan (2015) signale en outre que les travaux débordent de l'emprise spatiale qui leur a été affectée. Quoiqu'il en soit, le projet est actuellement en veille, l'investisseur coréen Hyundai, qui avait remporté le marché pour la construction de la SSB (Suai Supply Base), ayant été rejeté par la Chambre d'Audit pour corruption. Les travaux requis pour les aménagements prévus, SSB, autoroute et piste d'aviation agrandie, ont cependant été réalisés ou sont en cours, et ont déjà bouleversé la région.

Nous nous intéresserons ici plus particulièrement à la base d'approvisionnement SSB qui a été la première zone affectée par les travaux, et qui sera accompagnée d'un aéroport, d'un port et d'un parc de stockage du pétrole, d'une ville nouvelle, Nova Suai, et de deux réserves de crocodiles (sic) (Figure 2). L'aménagement, qui concerne pour la seule Supply Base $1113 \mathrm{ha}$, implique des déplacements de villages et des expropriations de terre, touchant principalement deux établissements de la région de Suai (district de Covalima) et leur territoire, ceux de Holbelis et de Kamanasa ${ }^{10}$.

Figure 2 : La région de Suai et les aménagements planifiés par le projet pétrolier

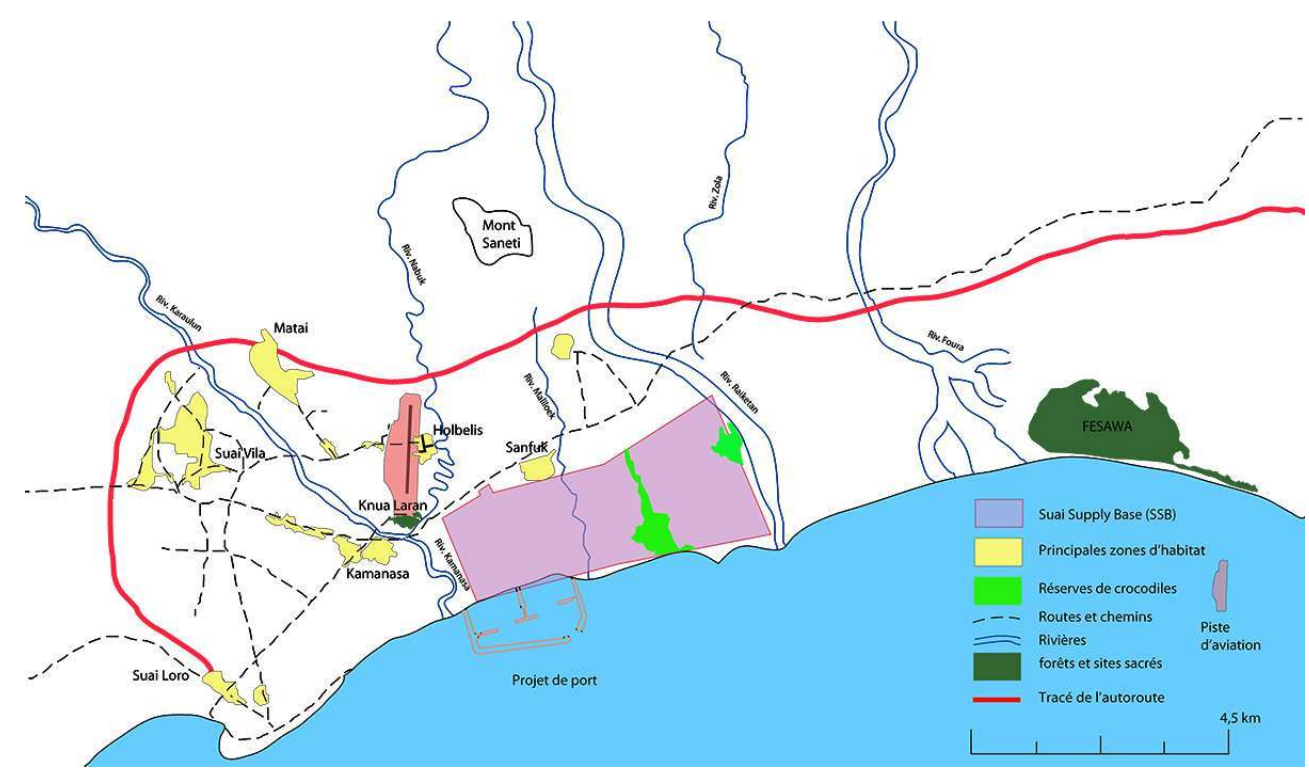

(c) B. Crespi

Concrètement, le projet prévoit le déplacement de la partie du village de Holbelis la plus proche de la piste d'aviation qui doit être agrandie (Figure 3). Holbelis, en bord de rivière, est un ancien site d'habitat des Tetun, chassés avant les années soixante par les Portugais testant là des cultures de coton et aujourd'hui installés dans un autre village, Fatisin. Après le départ des Portugais, le lieu est devenu un hameau temporaire de culture de Bunaq installés plus au nord. Devenu un site d'habitation permanent en 1962, il s'est 
étoffé en 1975-76 par les opérations menées par les Indonésiens pour rassembler les autres populations bunaq dispersées dans les collines en arrière de la côte. Le village bunaq est donc installé sur les terres qui étaient originellement celles des populations tetun. Ces derniers sont aussi touchés par le projet: une partie des terres de culture de Fatisin doivent être allouées au stockage du pétrole, mais l'enquête sur leur patrimoine est une étape ultérieure de notre travail.

Figure 3 : Les aménagements prévus dans la zone de Holbelis et Fatisin

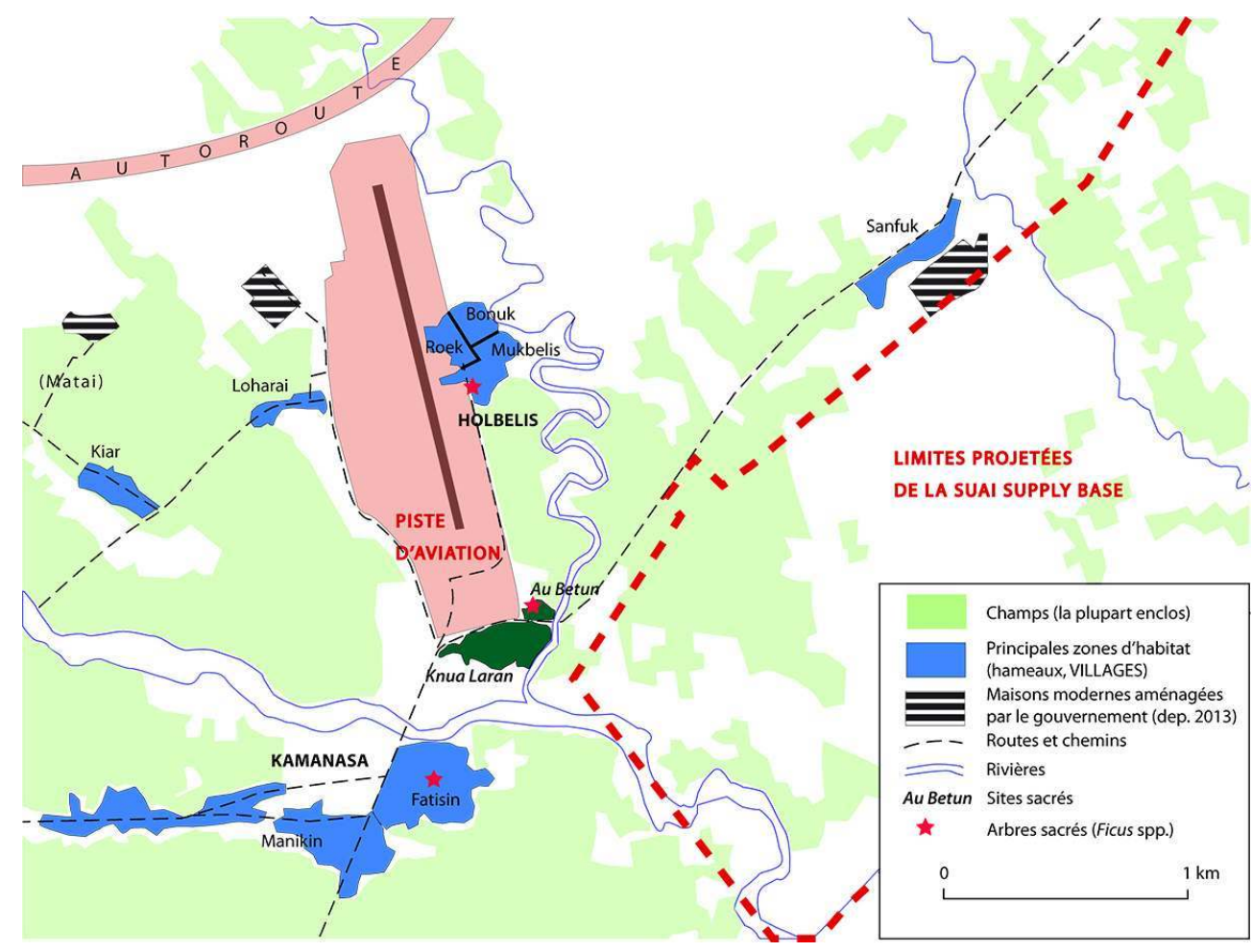

(C) B. Crespi/D. Guillaud

\section{Notre intervention avec un partenaire timorais : vers une cartographie participative du domaine lulik}

À l'indépendance, la petite ONG résistante Timor Aid $^{11}$ s'est reconvertie dans la promotion des cultures locales, et, associée à des chercheurs principalement australiens, s'est spécialisée dans les textiles traditionnels (tais) dans le but d'en conserver et commercialiser les productions régionales et soutenir ainsi les femmes qui les confectionnaient. En travaillant sur les techniques et savoirs des tais dans la région de Suai, les membres de l'ONG ont réalisé la connexion des diverses productions locales et envisagé une approche plus large de la culture pour la documenter dans son intégralité. Cette ouverture est aussi un moyen de diversifier l'organisation en sous-traitant certaines actions du gouvernement timorais dans le domaine de la culture.

Au départ, Timor Aid souhaitait soutenir face au projet pétrolier les communautés avec lesquelles l'ONG travaillait déjà, et visait comme résultat final une exposition destinée à documenter la culture des villages menacés par le projet ${ }^{12}$. Ils ont sollicité l'équipe IRD dans ce sens, qui leur a proposé une opération de cartographie participative et 
d'inventaire des patrimoines locaux. Outre Timor Aid, l'opération a été conduite en partenariat avec le Secrétariat d'État à la culture, qui avait des personnels dans chaque chef-lieu. Ces deux partenariats permettaient au projet de maîtriser les langues locales, une difficulté dans la région de Suai ${ }^{13}$, et d'avoir la caution d'institutions locales connues des communautés. Quant à la langue de travail au sein de l'équipe, elle a été une pierre d'achoppement car les discussions se déroulaient en tetun, indonésien, anglais, portugais, français...

23 Le projet de cartographie participative que nous avons élaboré ensemble sur le terrain devait permettre de fournir des éléments de discussion avec les promoteurs de l'aménagement. Il s'inspirait des expériences menées ailleurs par l'UMR Paloc, et se nourrissait de l'idée que, comme quasiment partout dans la région, l'approche spatiale était très pertinente dans le cas de ces sociétés puisant leurs références identitaires dans des trajets de migration et des itinéraires de maisons, davantage que dans des constructions généalogiques (Fox 2006).

Les modalités du projet ont été prédéfinies sur le terrain avec Timor Aid, et infléchies par les populations locales. En mai 2014, des entretiens menés avec les responsables de lignages, maîtres de la parole, chefs de villages et responsables coutumiers ont confirmé l'importance des maisons comme référent omniprésent de l'organisation sociale, et en particulier des maisons nobles. Plus précisément, l'approche entamée avec les populations locales a d'abord tenté de mettre en évidence ce qui faisait patrimoine pour celles-ci. Une fois le concept expliqué, le premier objet désigné comme relevant de cette catégorie a été la sorte de "trésor » que contient chaque maison lignagère, et qui est constitué par l'addition au fil des générations d'un ou plusieurs objets relevant du chef de clan et qui lui sont personnels ou emblématiques. Il apparaît ainsi que c'est bien ce trésor qui dans la maison a un caractère sacré (lulik), davantage que la maison elle-même. Cependant ce trésor, dont les pièces de valeur comme les textiles, armes, gongs, ont été pour la plupart détruites ou vendues, n'est pas destiné à être montré. Ce sont donc les maisons qui lui servent d'écrin et auxquelles il confère son caractère sacré qui ont été désignées comme les patrimoines à enregistrer (Figures 4 et 5). Ces maisons ont encore pour beaucoup une apparence "traditionnelle", car elles sont édifiées avec des matériaux végétaux, mais elles ont toutes été détruites deux fois, en 1975 et en 1999, et ont été reconstruites à l'identique. Certaines maisons ont été reconstruites en ciment, mais les maisons nobles sont toujours en matériaux végétaux. 
Figure 4 : Babulu, maison la plus haute du village de Holbelis

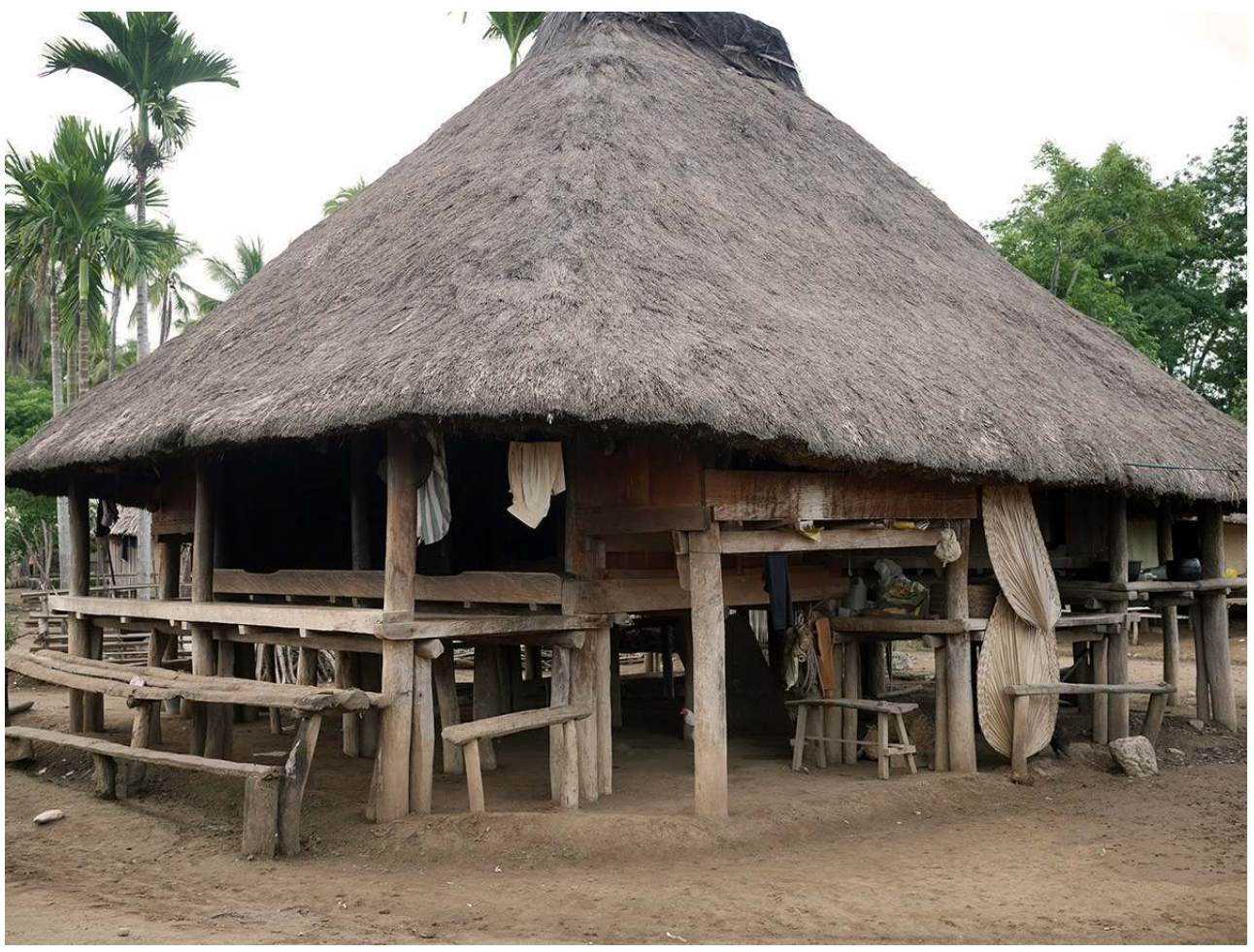

(c) J.-C. Galipaud

Figure 5 : Maison bunaq de Holbelis ; devant, un autel KAKALUK

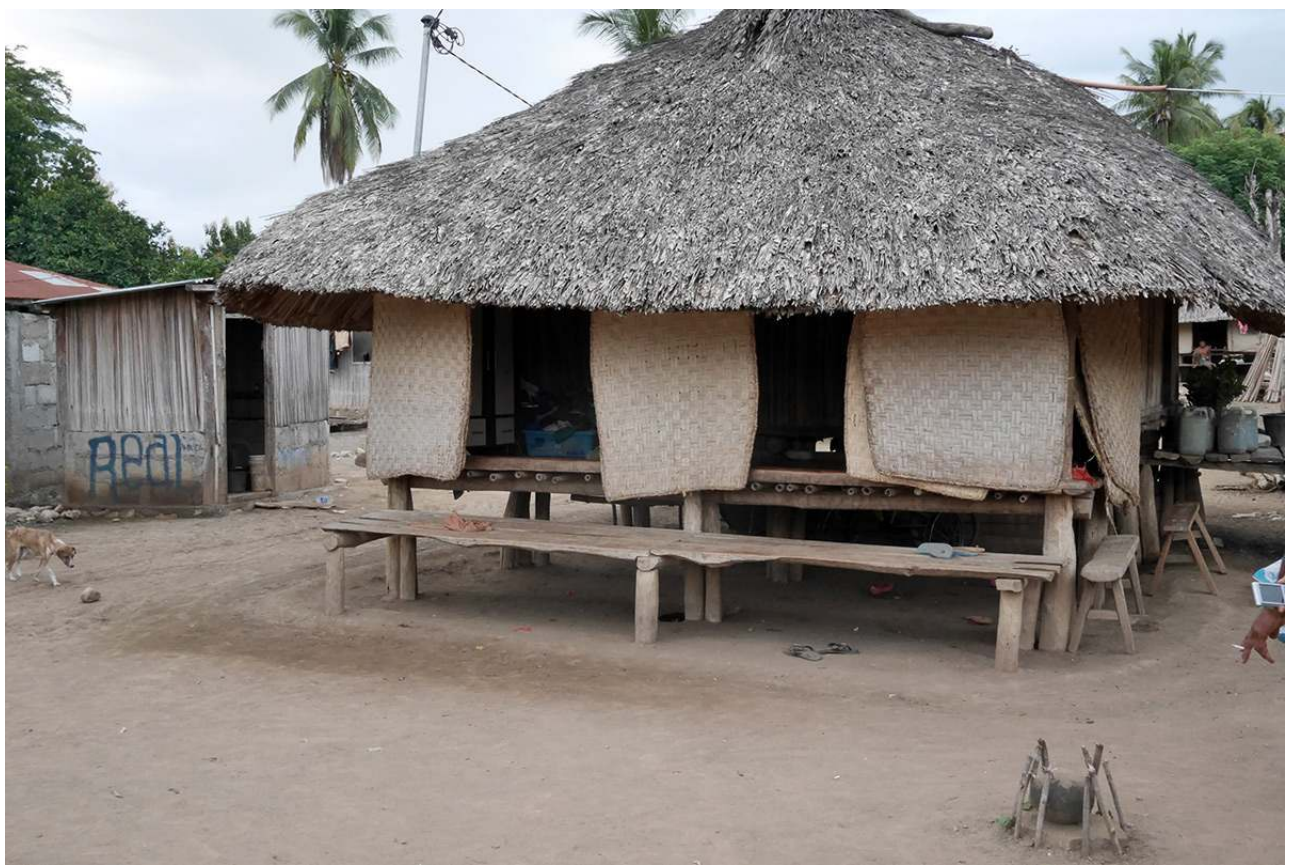

(C) J.-C. Galipaud

Des parcours de terrain en compagnie des responsables locaux nous ont amenés à percevoir d'autres éléments relevant du domaine sacré : des arbres, comme le banian 
central des villages tetun ${ }^{14}$ (Figure 6), des autels (kakaluk et sadan) associés à certaines maisons ou à certains statuts chez les Bunaq (Figures 7 et 8), des puits réservés aux cérémonies, venaient compléter le panorama des éléments patrimoniaux de l'espace domestique centré autour des maisons. A une échelle plus réduite, les champs constituent également un domaine où les rituels révèlent des espaces et une organisation spécifiques : sur les autels centraux (Figure 9), visibles car marqués par des pierres ou des poteaux et des plantes particulières, les semences sont chargées de la puissance magique qui permettra leur croissance, tandis que chaque coin du champ est le domaine d'esprits qui doivent être amadoués par des offrandes afin qu'ils ne viennent pas perturber la pousse des plantes. Dans les espaces de culture hors du village, des tombes en ciment balisent l'espace. Elles signalent souvent les tragédies de l'histoire récente, que les informateurs rappellent : des pierres tombales figurant des fusils indiquent la sépulture d'un membre de la résistance, d'autres tombes des familles entières décimées par la malaria au temps des Indonésiens.

Figure 6 : Banian au centre du village tetun de Fatisin ; en arrière : la plus haute maison de Fatisin (Uma metan)

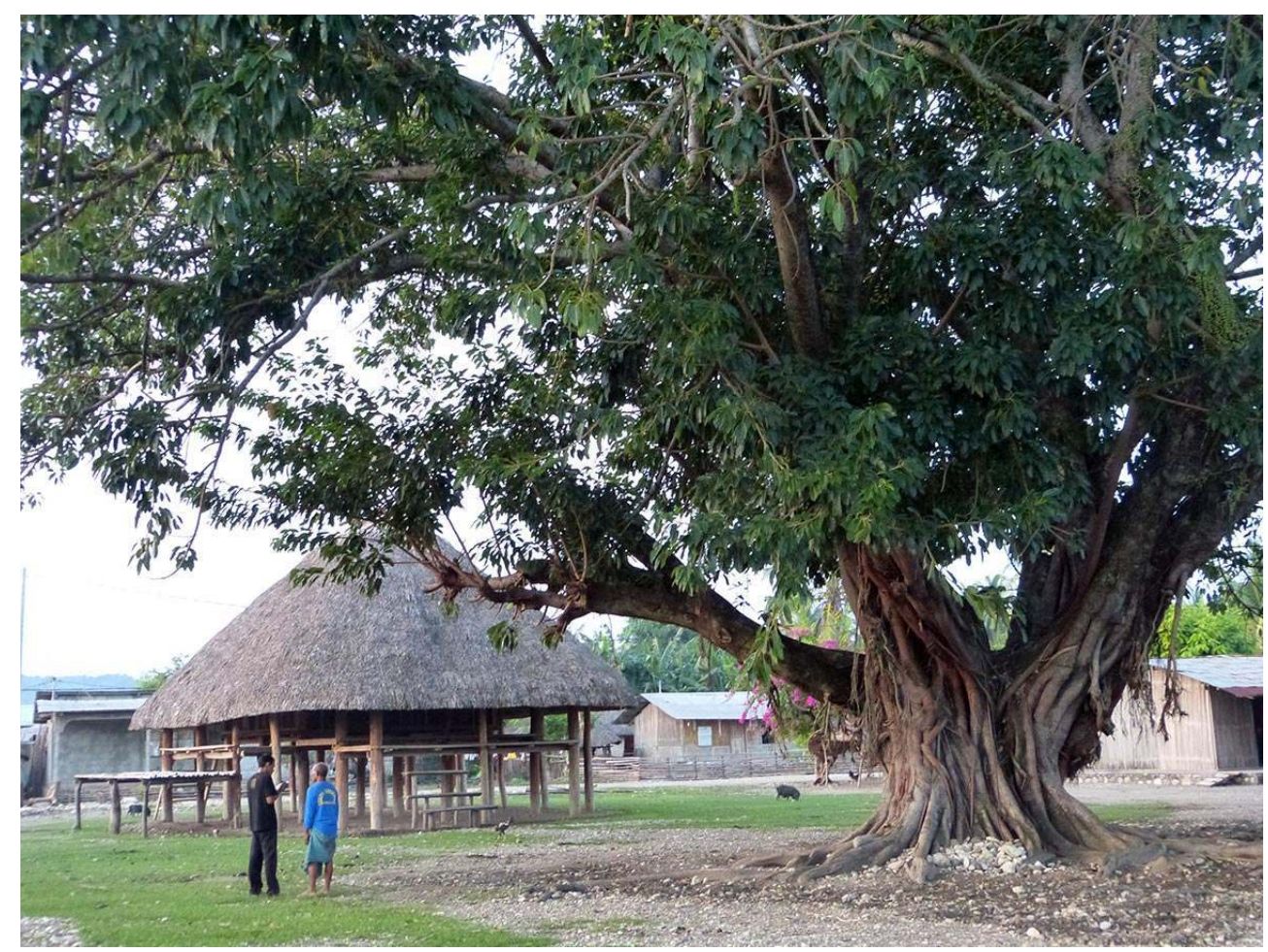

(C) D. Guillaud 
Figure 7 : Autel SADAN dans le village de Holbelis

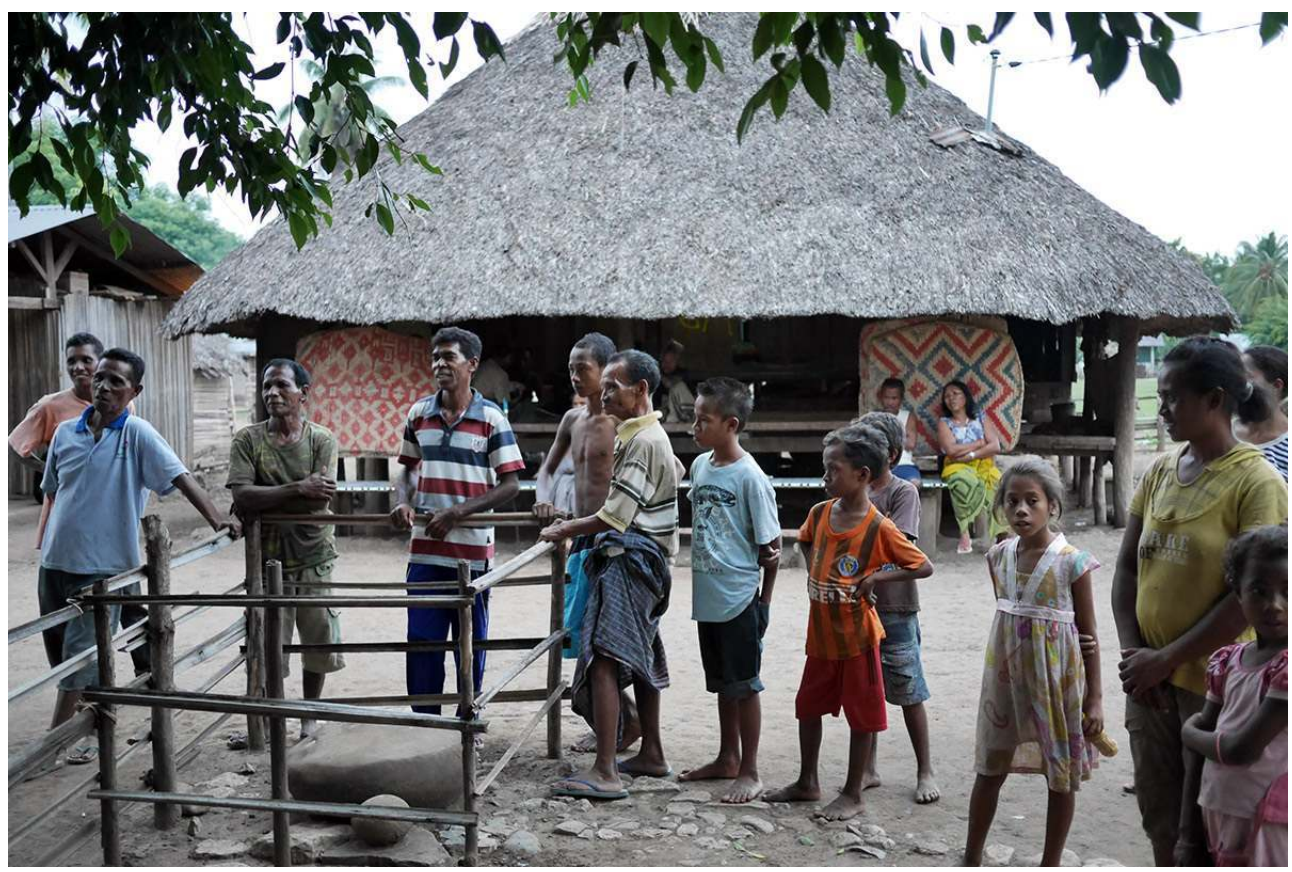

(c) J.-C. Galipaud

Figure 8 : Autel KAKALUK, Holbelis

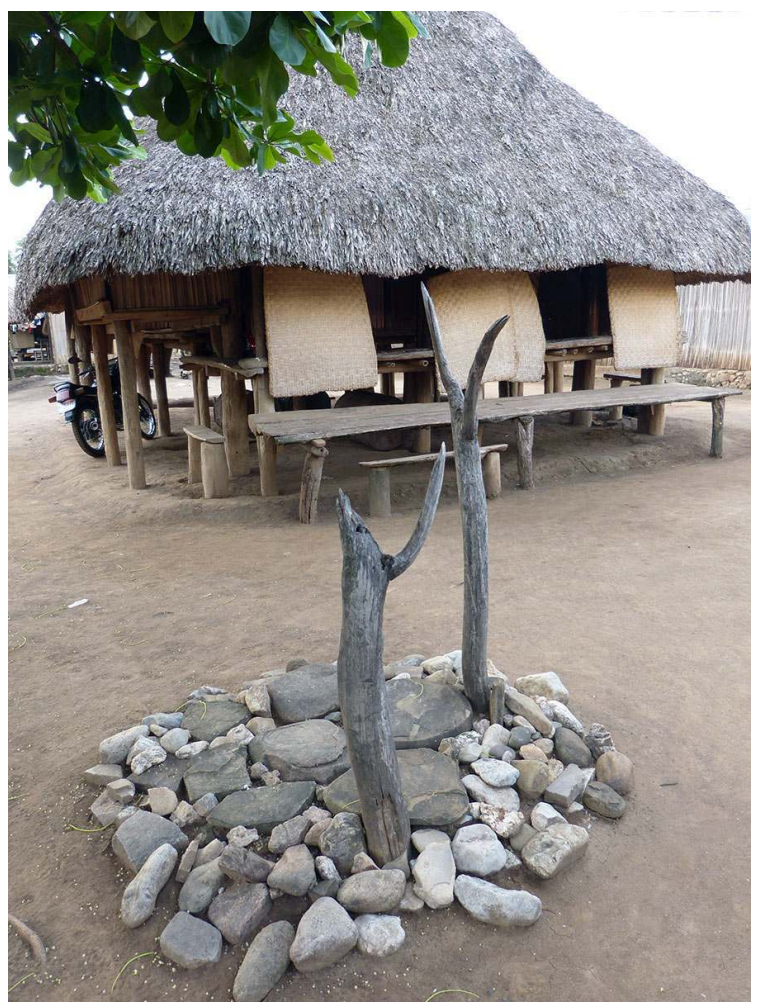

(C) J.-C. Galipaud 
Figure 9 : Autel de champ UMON : pierres et poteau, Holbelis

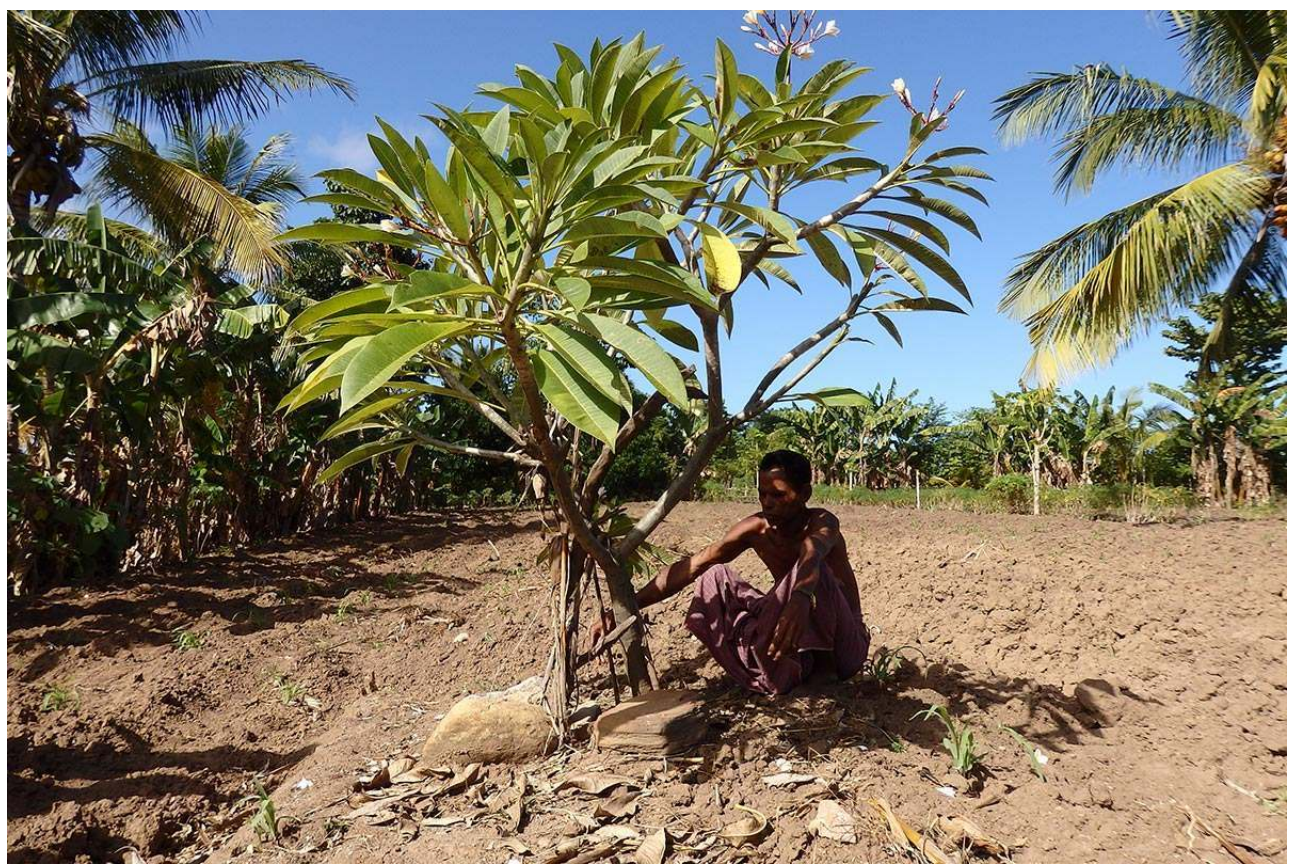

(c) L. Emperaire

Hors des villages, d'autres éléments signalés comme très importants, localisés et cartographiés, ont révélé les différentes échelles de ce patrimoine villageois. D’anciens lieux d'établissement du groupe, comportant souvent des tombes, ou les lieux mentionnés dans les récits mythiques comme lieux d'origine sont fréquentés lors des cérémonies. Des forêts frappées d'interdits à différents degrés sont aussi des lieux extrêmement forts de l'organisation villageoise (forêt de Knua Laran ; Figure 10). 
Figure 10 : Forêt sacrée de Knua Laran, Kamanasa

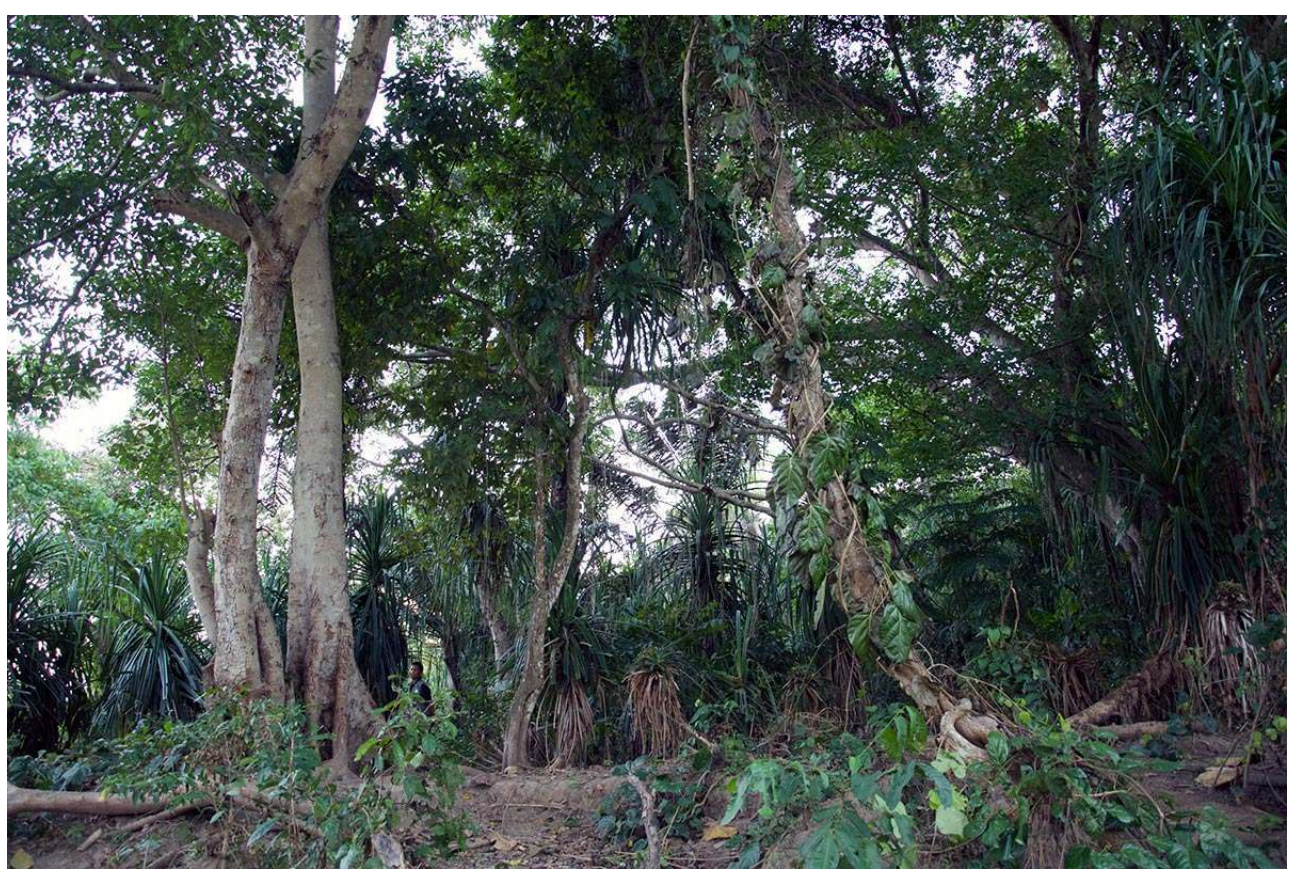

(c) B. Crespi

Des éléments dynamiques ont également été décelés comme investis d'une valeur patrimoniale, tels les circuits rituels, révélant les liens entre divers éléments sacralisés. Les cérémonies des prémices du maïs mobilisent toute la population qui se rassemble autour des plus basses des maisons nobles, puis entame un cheminement dans le village en remontant la hiérarchie des maisons nobles pour aboutir à la plus haute d'entre elles. Les récits de la tradition orale et certains savoirs sur les temps anciens constituaient également des éléments patrimoniaux, transmis entre les générations et chargés de lourds enjeux car destinés à définir les responsabilités actuelles de chaque groupe dans la société. Le droit de les énoncer est en principe l'apanage des maîtres de la parole, mais tous les connaissent et beaucoup les invoquent aujourd'hui, surtout avec la perspective des compensations financières pour la terre et les cultures que le projet pétrolier a fait naître.

Le recueil de l'ensemble a permis une approche intéressante des faits de territorialité et des lieux forts, tout en rendant compte de façon relativement fidèle de ce qui constituait le patrimoine de ces villageois, et au-delà, des lignes de force de la société toute entière. Symptomatiquement, l'inventaire nous ramenait sans cesse au lien étroit entre sacré et patrimoine. Le concept de lulik que nous avons traduit par «sacré » renvoie à l'univers des forces «souterraines » et ancestrales (Bovensiepen \& Delgado 2016) des non-humains qui conditionnent le fonctionnement du monde humain, et imprègnent l'ensemble du territoire. Comme le souligne Terik (2004: 186), cette notion de lulik est très liée à l'espace et aux lieux, qui sont considérés comme sacrés car ils fonctionnent comme des points de communication entre le monde sacré «d'en-dessous » et le monde séculier « d'au-dessus ». La cartographie du domaine sacré se superpose plus ou moins à celle du territoire, mais le sacré n'a pas toujours une traduction matérielle évidente, désignant là les limites de la cartographie. Des " gradients de sacralité " sont également apparus, définissant un domaine à explorer et à formaliser, tous les lieux et tous les savoirs ne se 
valant pas. Si certains sites comme Knua Laran (la grande forêt sacrée des Tetun, et également un ancien établissement ainsi qu'un lieu de sépulture royale) sont une référence absolue, d'autres sites ne concernent qu'une fraction de la population et ont une importance moindre.

$\mathrm{Au}$ fil des entretiens, la biodiversité est également apparue comme un domaine patrimonial important. La biodiversité cultivée notamment a permis de fournir quelques indices sur l'histoire agricole de la région. Les discussions sur les plantes actuelles et anciennes étaient prises très au sérieux par nos informateurs, qui ont insisté pour nous montrer un échantillon de toutes les plantes dont ils nous parlaient et ont convoqué spontanément plusieurs personnes âgées, à même de décrire des situations anciennes (Figure 11). Ces éléments ont été intégrés dans les expositions de 2015 et 2016.

Figure 11 : Collecte de céréales pour les entretiens sur les plantes cultivées ; millet et divers haricots

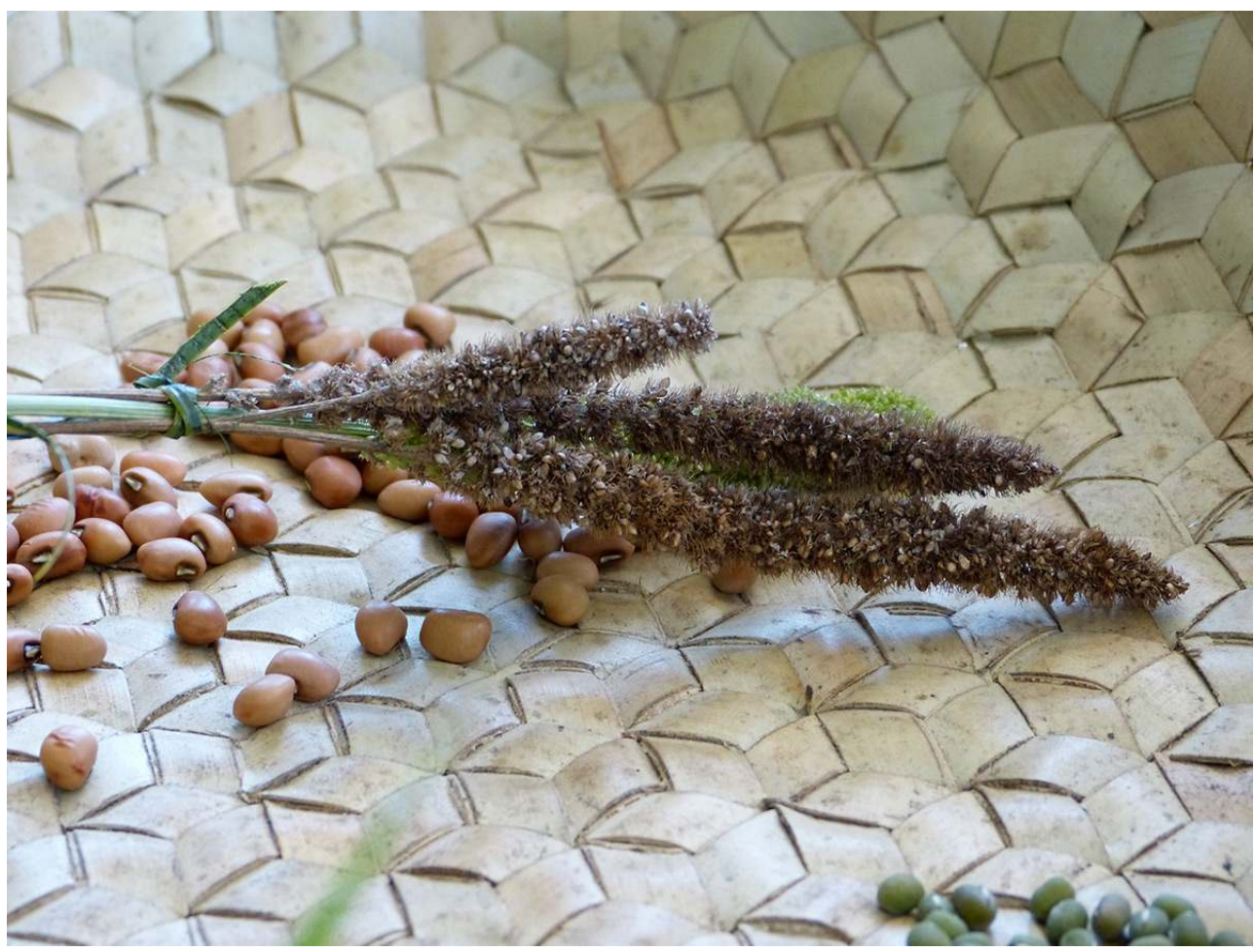

(c) D. Guillaud

Les relevés de terrain proprement dits, assortis d'entretiens pour la plupart enregistrés, se sont déroulés en mai et novembre 2014 et 2015 pour le village d'Holbelis ${ }^{15}$. Ils ont consisté en parcours de terrain guidés par des informateurs (le chef coutumier, un ancien instituteur, etc.) qui désignaient les éléments importants de leur culture locale, et organisaient des étapes dans les maisons où des entretiens étaient menés. Ils étaient assortis de localisations GPS, avec l'aide d'une fiche standardisée pour documenter les maisons. Chacune des maisons lignagères a été photographiée, parfois son autel également. Les autres sites hors du village ont été repérés, rapidement levés et leur potentiel archéologique évalué. A quelques rares reprises il nous a été demandé de ne pas photographier certains sites, mais l'interdiction est apparue davantage liée à la légitimité de celui qui faisait visiter le lieu qu'à un interdit véritable: en présence du responsable légitime, la photo est devenue possible. 

remarquable est tenu par les érudits, des enseignants (anciens professeurs de portugais, instituteurs) qui ont été mis en avant par les responsables coutumiers comme intermédiaires censés nous appuyer dans la compréhension de la coutume. Ils tendent parfois à simplifier les explications pour les rendre plus accessibles mais sont souvent des appuis précieux. Certains d'entre eux ont aussi des positions coutumières (lianain) qui leur donnent le droit d'énoncer des récits, qu'ils jugent important de transcrire (pour qu'ils ne soient pas oubliés des générations à venir, pour garantir durablement leur statut social et territorial, ou pour faire reconnaître leur culture à l'extérieur).

ntion particulière, enfin, est à réserver aux femmes, qui occupent un rôle important dans ces sociétés matrilinéaires et matrilocales. Les femmes ne s'expriment pas directement sur l'histoire ou la position de leur maison, car c'est leur frère qui doit parler à leur place, et à ce que nous avons pu observer, aussi leur mari. Néanmoins elles sont présentes lors des entretiens et, au moment de la photo, demandent à poser sur le seuil de la maison qui leur appartient, parfois avec leur époux; les hommes, quant à eux, posent seuls devant leur autel de guerre (kakaluk). 


\section{Demandes locales et résultats : les enjeux de la cartographie}

Devant cette diversité extrême d'acteurs et d'intérêts, la collecte d'informations s'est d'abord concentrée sur les éléments tangibles de la culture locale, qui puissent produire une base consensuelle entre les différents protagonistes de la vie villageoise. Les entretiens enregistrés en tetun ou bunaq ont été transcrits en anglais par Timor Aid et les informations concernant les éléments tangibles précédents ont été réinjectés dans le fichier des maisons. Nous avons ainsi abouti à une cartographie des maisons (Figures 12 et 13) à laquelle était assortie une série de fiches renseignant les caractéristiques et le statut, l'architecture et les autels associés, avec les photos correspondantes.

Figure 12 : Cartographie des maisons sacrées, Holbelis

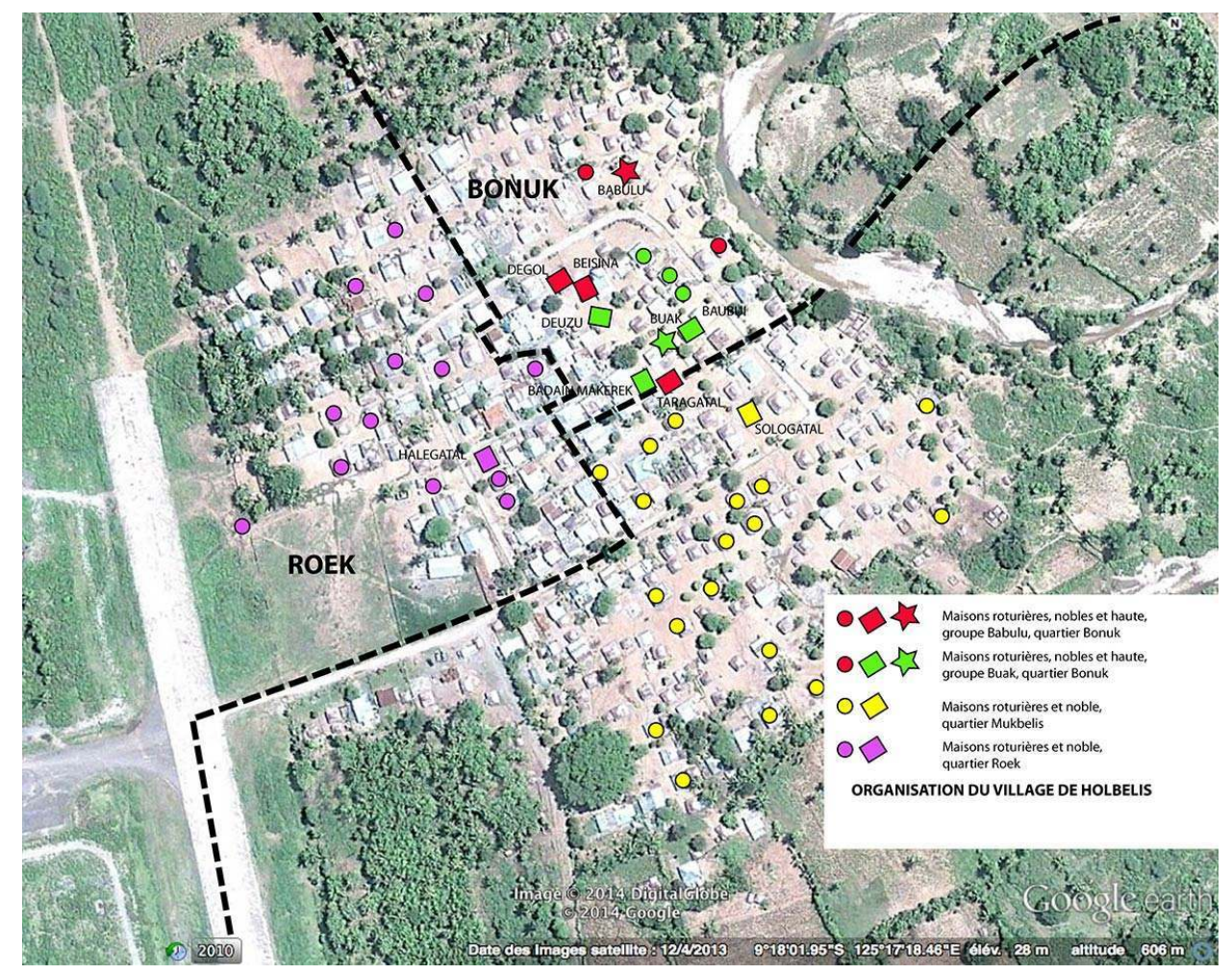

(C) Google Earth / IRD 
Figure 13 : Cartographie des maisons sacrées, Fatisin

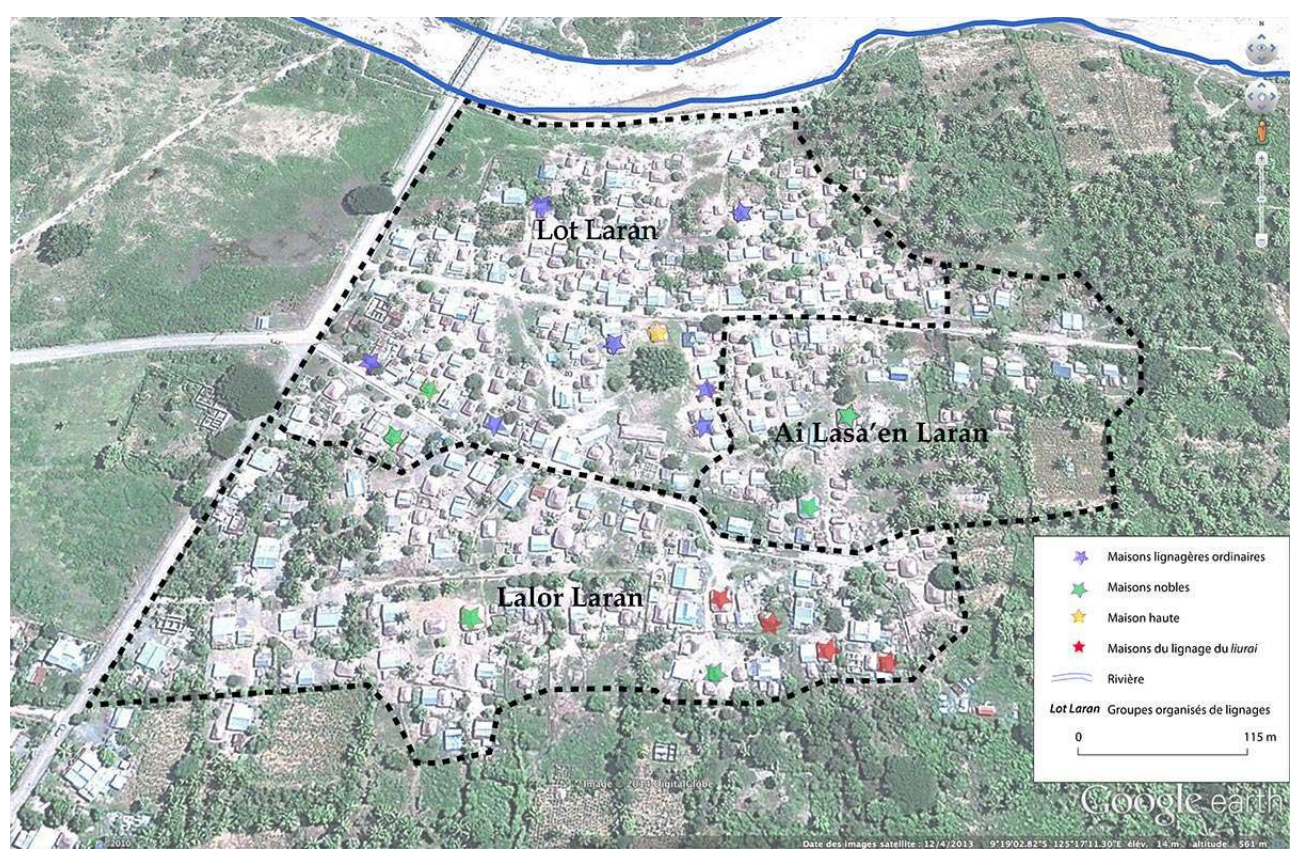

(c) Google Earth / B. Crespi

Les récits de la tradition orale pour leur part, qui se déclinent en plusieurs variantes, ont fait l'objet d'un essai de cartographie qui a été ensuite soumis aux populations de Holbelis. Celles-ci ont validé les itinéraires et les migrations présentés dans les récits, mais ont souhaité que les récits restent oraux, expliquant que des variantes existaient et qu'il n'était pas nécessaire de faire naître des contestations en les représentant sur une carte. Le groupe de langue bunaq de Holbelis est établi sur des terres qui leur ont été allouées il y a deux générations par les Tetun; la situation entre les deux groupes s'est tendue depuis les débuts du projet Tasi Mane, et les Bunaq ne souhaitent pas attiser les conflits - déjà nombreux - en affichant leurs prétentions sur les terres qu'ils exploitent.

En juillet 2016, une exposition/restitution aux populations a été faite à Suai sous l'égide de Timor Aid, autour de la cartographie et de la culture matérielle (les superbes textiles de Covalima, mais aussi la poterie et l'agrobiodiversité) (Figures 14, 15 et 16) et le premier Ministre de Timor-Leste est venu l'inaugurer. Les lianain tetun de Fatisin se sont rendus à l'inauguration en grande tenue traditionnelle pour recevoir l'hommage rendu à leur culture autour des textiles, des plantes cultivées et de la céramique; en revanche les cartes présentées ne répondait pas à leurs attentes, ne figurant encore que le village bunaq de Holbelis, et ils sont repartis déçus (Figure 17). Les habitants de Holbelis, pour leur part, ne se sont pas déplacés, faisant savoir qu'ils étaient aux prises avec d'importants problèmes liés à des conflits de bétail. 
Figure 14 : Textiles de Suai, collection de Timor Aid

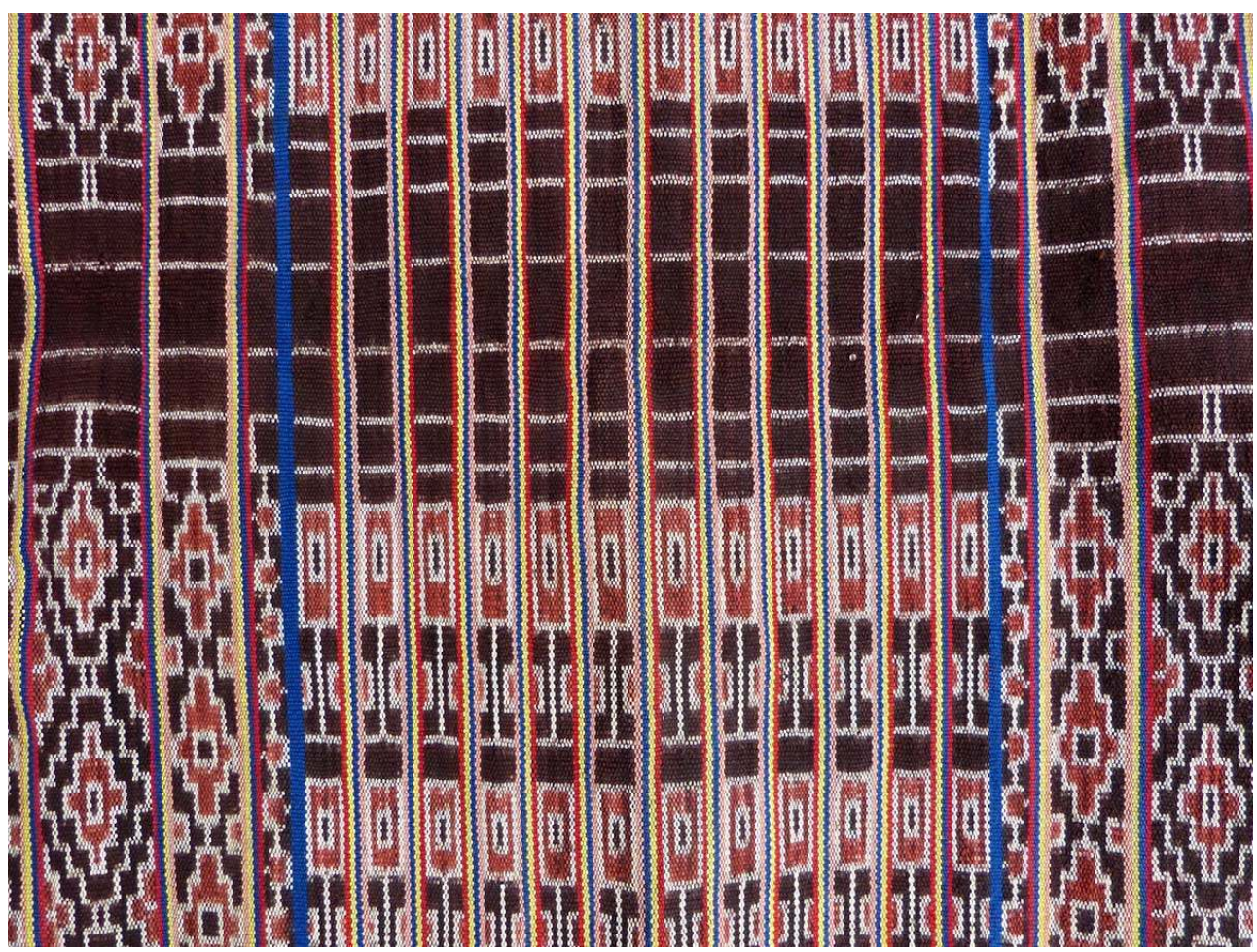

(C) D. Guillaud

Figure 15 : Textiles de Suai, collection de Timor Aid

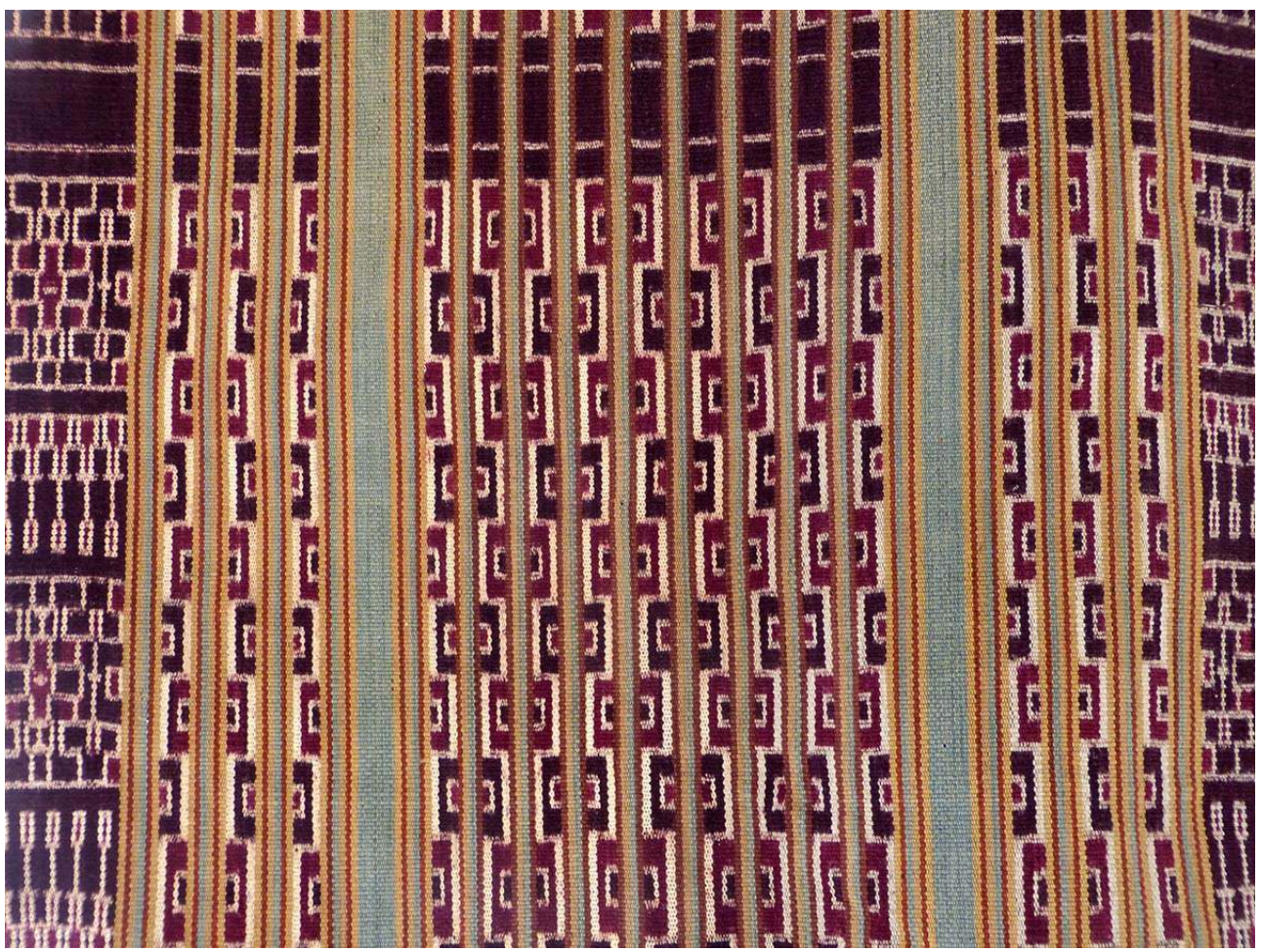

(c) D. Guillaud 
Figure 16 : Textiles de Suai, collection de Timor Aid

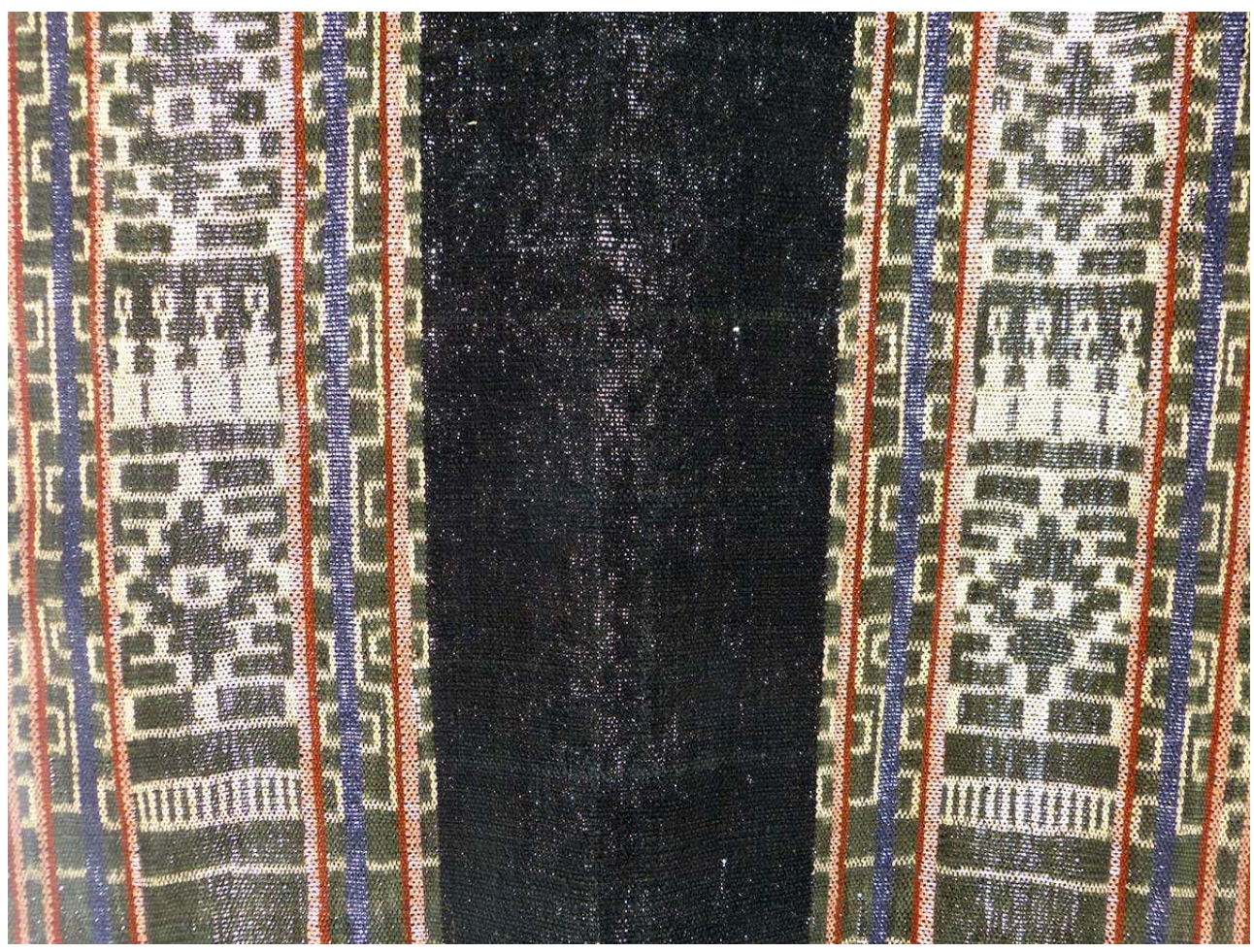

(c) D. Guillaud

Figure 17: Les coutumiers de Fatisin à la restitution de 2016

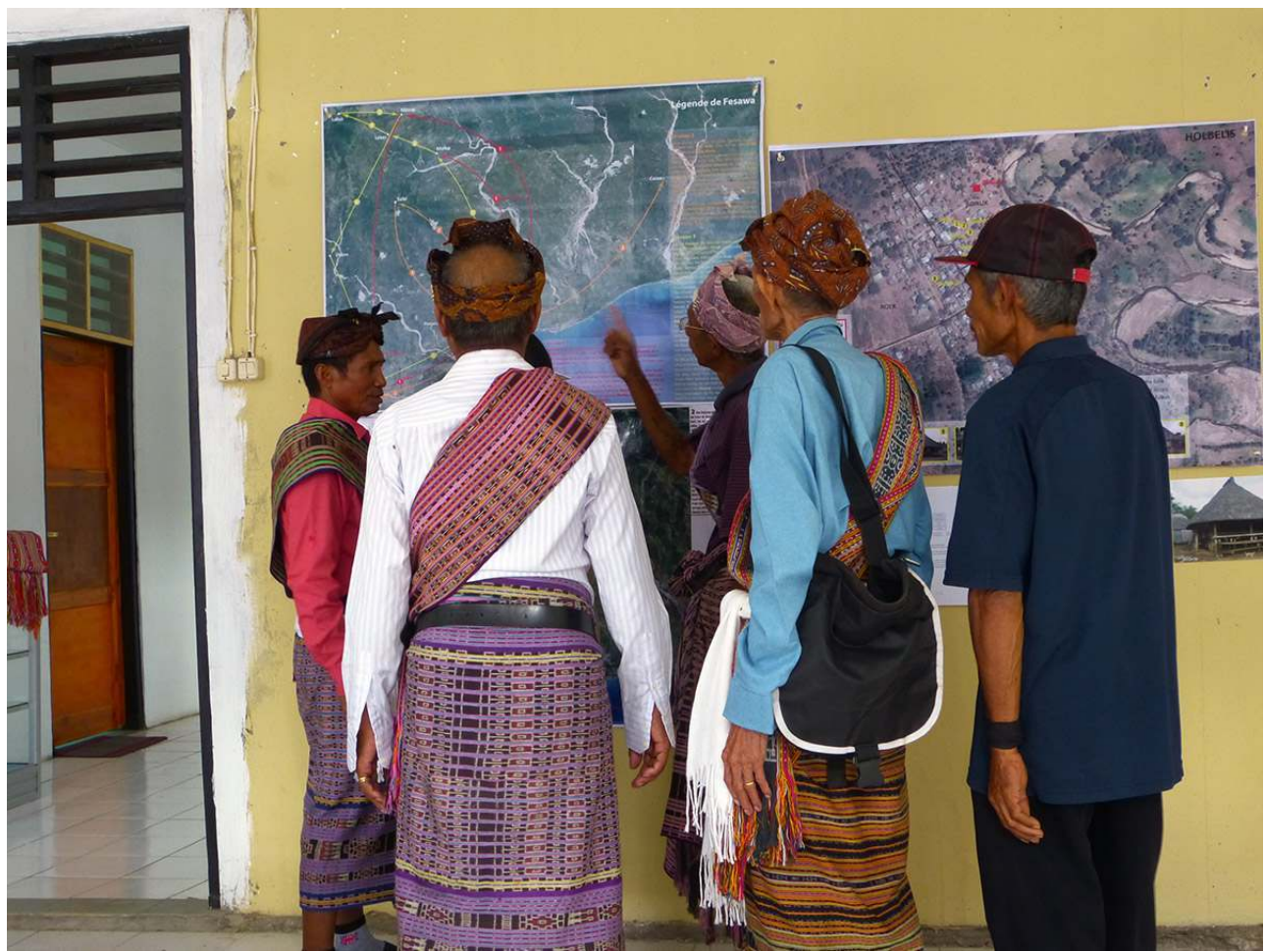

(c) D. Guillaud 
Des travaux similaires sont toujours conduits dans l'autre village, Kamanasa, par Brunna Crespi, qui doit venir en novembre 2017 restituer ses travaux aux villageois. Quant à l'ONG Timor Aid, dans un rôle d'apprentissage au départ, elle souhaite généraliser cette approche à d'autres sites concernés par l'aménagement pétrolier.

\section{Lîle d'Ataúro : les patrimoines locaux au tournant du tourisme}

\section{L'émergence du projet de développement touristique}

Cette petite île d'environ $140 \mathrm{~km}^{2}$, anciennement appelée l'île aux Chèvres, est située à une trentaine de kilomètres au nord de Dili, district auquel elle est rattachée administrativement. Avec 8602 habitants recensés en 2010 (Ministry of Finances 2015), son organisation administrative en cinq suku est loin de rendre compte de sa diversité socio-culturelle (Figure 18). Diversité linguistique ${ }^{17}$, diversité des formes d'inscription dans le temps et l'espace et diversité des formes d'organisation sociale sont encore extrêmement saillantes en dépit de l'enchaînement des occupations portugaise et indonésienne, de la christianisation catholique, protestante et aujourd'hui évangélique qui les a accompagnées. L'occupation indonésienne a aussi imposé des reconfigurations spatiales des maisons lignagères, autrefois dispersées, en villages tirés au cordeau. Les travaux réalisés dans les villages de Makadade et de Arlo, respectivement situés au sud de l'île dans la zone volcanique dominée par le sommet de Manukoko (999 m) et, plus au nord, dans les plateaux coralliens montrent que chaque localité a une histoire spécifique faites de guerres et d'alliances qui se prolongent encore dans les rapports entre groupes linguistiques et entre maisons lignagères. L'île est parsemée de murets de grosses pierres qui marquent les limites entre les lignages (Figure 19), limites désignées comme l'objet des guerres de la morte-saison, et de sites fortifiés aux murailles multiples et aux accès en chicane ou en goulot (Figure 20). Ces traces marquent l'hostilité ancienne qui caractérisait les contacts entre les groupes humains, et teinte encore leurs relations. 
Figure 18 : Chef-lieu de Vila, Ataúro

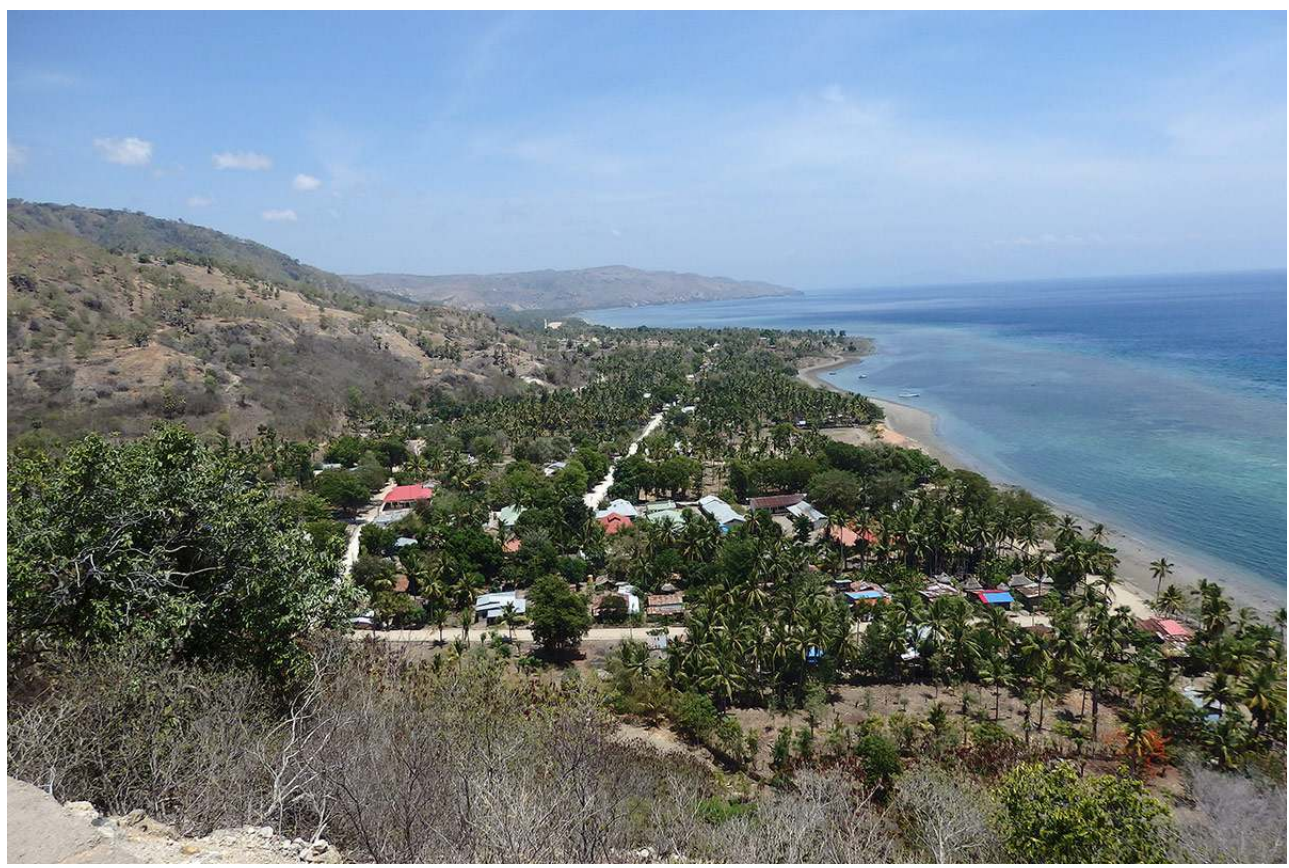

(c) L. Emperaire

Figure 19 : Échelle pour franchir un muret, Makadade

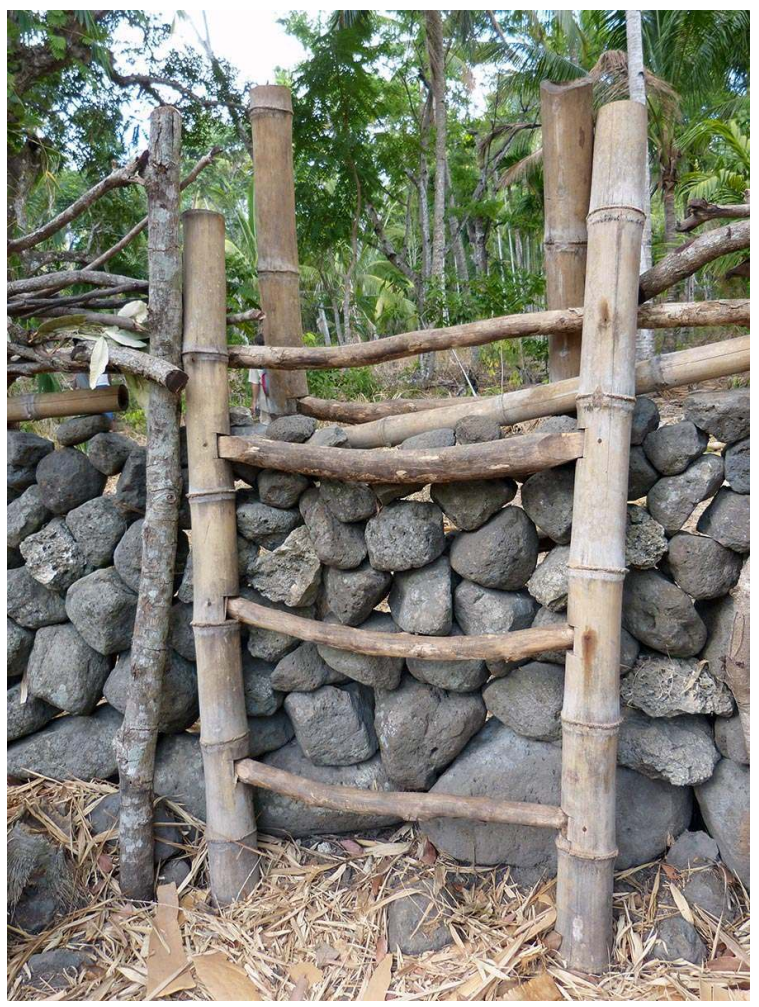

(C) D. Guillaud 
Figure 20 : Entrée en goulot sur un site fortifié, région de Makadade

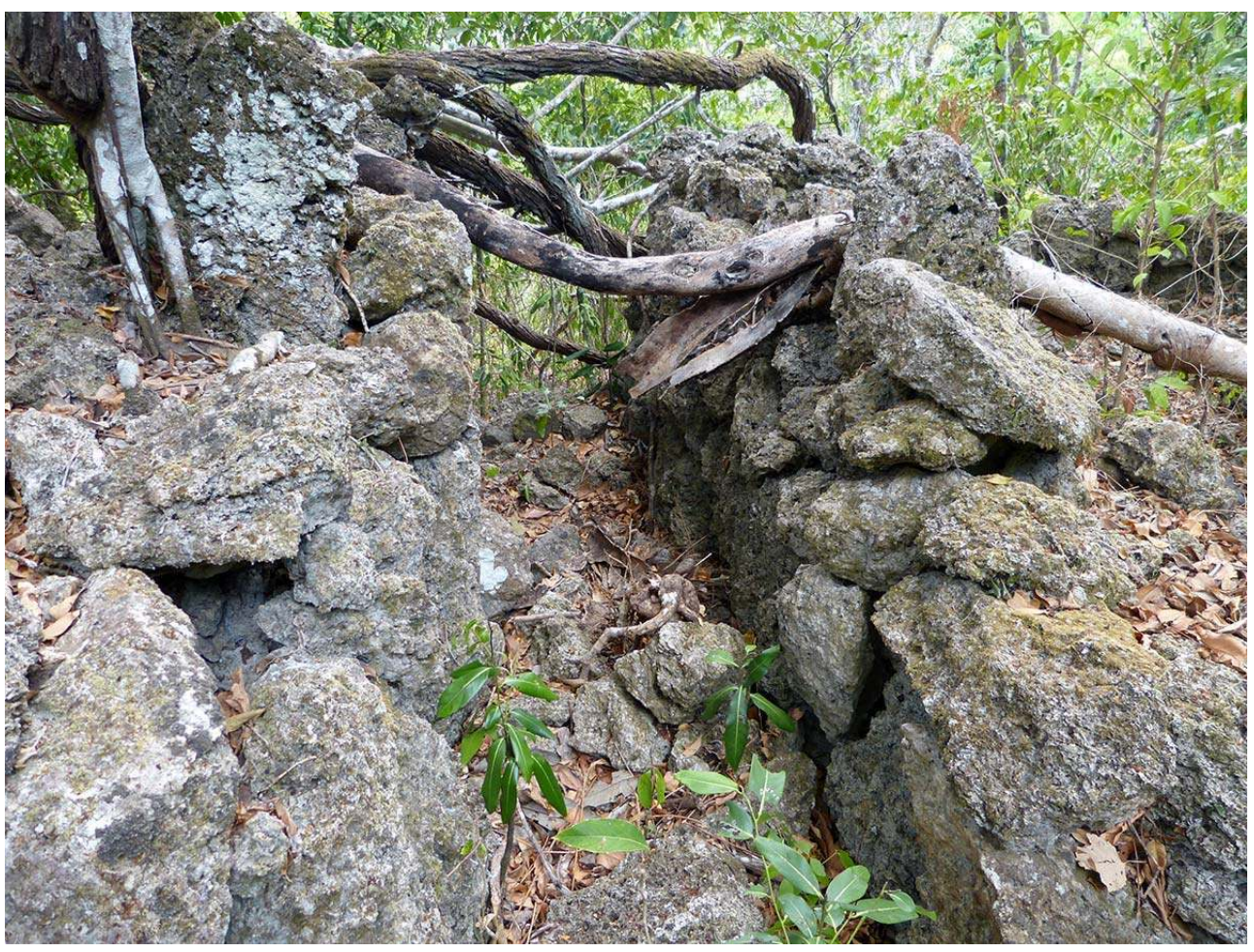

(c) D. Guillaud

42 L'île vit essentiellement de ses activités traditionnelles, pêche et agriculture, d'un écotourisme émergeant lié à la richesse de sa faune sous-marine, et de quelques activités commerciales et administratives. Malgré l'existence de petits marchés locaux, Ataúro est en grande partie approvisionné par des denrées et biens manufacturés venus de Dili, capitale elle-même approvisionnée en grande partie par l'Indonésie. Avec un climat de type semi-aride, la question de l'eau est omniprésente sur l'île pour la vie quotidienne comme pour l'agriculture. L'infrastructure est aujourd'hui limitée à deux tronçons de routes empierrées et à une petite piste d'atterrissage. Mais la mise en place d'un projet de développement du tourisme et de modernisation de l'infrastructure (routes, électricité, aéroport) est en passe de changer profondément cette configuration.

Le plan de développement touristique repose sur des articulations politiques et territoriales. Ataúro a été intégré en 2015 à la ZEESM (Zone spéciale d'économie sociale de marché /Zona Especial de Economia Social de Mercado), opérateur financier du développement de la zone d'Oe-cusse (enclave historique de Timor-Leste située dans le Timor indonésien). La ZEESM est dirigée, à la suite de négociations politiques avec le pouvoir central, par un ancien résistant et opposant au pouvoir actuel. La mise en place du projet touristique a pour première base documentaire le plan de gestion territoriale de l'île (Plano de Ordenamento do Território da Ilha de Ataúro) approuvé par le conseil des ministres en février $2016^{18}$. Localement, ses retombées (électrification, accès à l'eau, développement $\mathrm{du}$ réseau routier) sont vivement attendues mais, comme le mentionnaient Cabasset-Semedo \& Durand (2009) il y a une dizaine d'années, qu'il s'agisse d'impacts identifiés comme positifs ou négatifs, la rumeur prime encore sur l'information. 
Les principaux éléments qui constituent la base argumentaire du projet sont la richesse des fonds marins (avec des activités de plongée et de snorkeling) (Figures 21 et 22), un tourisme de type trekking et l'observation de la biodiversité, la connaissance du patrimoine culturel de l'île et un tourisme de type balnéaire. Malgré l'accent mis sur le rôle des populations locales, force est de constater qu'à Ataúro, elles ne sont au courant que très indirectement de ce projet touristique dont elles attendent beaucoup, notamment en termes d'infrastructures (eau, électricité et routes, pour le moment limitées à quelques localités de l'est), et en termes d'emplois. La question globale des tensions entre normes légales et coutumières, que cela soit dans les domaines du foncier, de l'accès à l'eau douce, aux ressources halieutiques etc., celle des droits intellectuels, collectifs ou individuels, qui opèrent sur les patrimoines locaux, et des choix à opérer dans leur formes de valorisation n'est pas posée dans le plan de gestion territoriale. Et si celui-ci prend en compte la richesse patrimoniale des différents groupes culturels de l'île comme ressource d'intérêt économique, leur intérêt écologique en matière de gestion durable du territoire et de ses ressources demeure, comme dans d'autres contextes, invisible aux yeux des pouvoirs publics.

Figure 21 : La faune sous marine représentée par un habitant, Arlo

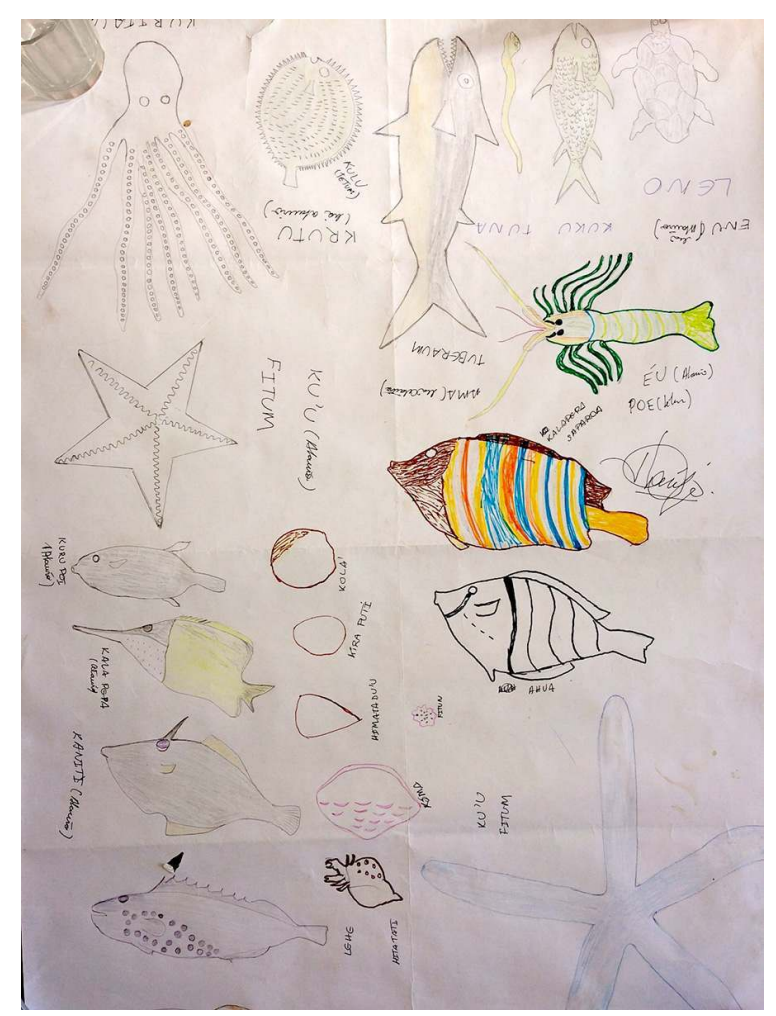

(C) D. Guillaud 
Figure 22 : Touristes à Adara

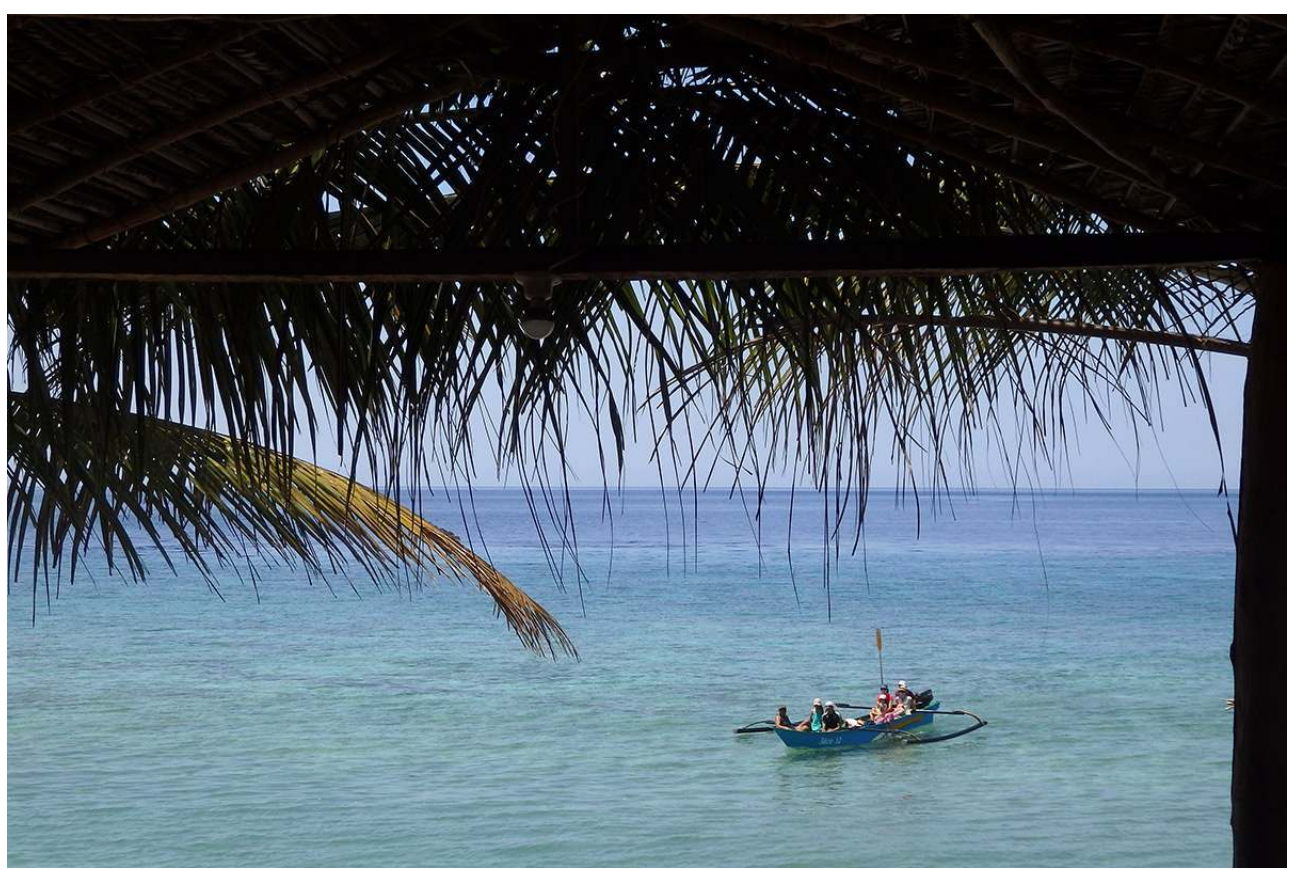

(c) L. Emperaire

\section{La recherche et son « tournant participatif »}

Le groupe de recherche, interdisciplinaire, dispose aujourd'hui d'un recul et d'un corpus de données qui permet d'avancer des propositions de consolidation et de valorisation des patrimoines locaux en s'intéressant aux objets patrimoniaux matériels ou immatériels en jeu, à leurs conditions de production et aux acteurs impliqués. Sa problématique, initialement centrée sur l'identification des patrimoines locaux archéologiques et géographiques à partir de la perspective locale, et sur leur valeur heuristique pour la compréhension du peuplement et de l'organisation sociale de l'île, s'est doublée d'une part d'un volet appliqué sur la gouvernance locale des patrimoines et de l'autre d'une réflexion sur la prise en compte des demandes locales dans la définition des politiques culturelles ${ }^{19}$.

La période de 2013 à aujourd'hui - et pour les années à venir - est celle de la construction d'un processus collaboratif sur la mise en valeur des patrimoines, avec en toile de fond la complexité et l'enchevêtrement des histoires et des relations au territoire des villages et hameaux et le projet touristique. Quels sont les acteurs mobilisés, comment évolue la posture du chercheur, d'observateur à catalyseur ? Quelles sont les conditions de réalisation de la recherche et, comment répondre au préalable fermement posé par le jeune chef de village de Makili intéressé par notre démarche ? "[Oui, d'accord pour parler de nous mais] avec nous et pour nous ".

Avec quelques variations selon les lieux et les interlocuteurs, les recherches ont suivi le même déroulement. Le point de départ de toute activité scientifique sur l'île est la remise des autorisations émanant du Secrétariat à la Culture aux autorités locales, les cinq chefs de suco et les chefs des villages (aldeia) concernés par les recherches. Centrées initialement sur les récits d'origine, leur inscription spatiale et les territoires des maisons 
lignagères, elles se sont appuyées sur un relevé commenté du territoire avec l'enregistrement des cheminements et des localisations au GPS des géosymboles (Bonnemaison 1981). Cet ancrage géographique a été complété par des enquêtes, encore non totalement abouties, sur la localisation, les savoirs, normes et pratiques de gestion des ressources, pêche, agriculture et ressources végétales forestières et autres thèmes d'intérêt des villageois. La démarche de terrain croisée à celle de cartographie participative a permis de caractériser graphiquement des limites, des cours d'eau, des reliefs, etc. Les éléments de la biodiversité ou de la culture matérielle ont également été illustrés et commentés au village.

De ces échanges et parcours résultent des représentations de l'île selon un emboitement d'échelles. De celle qui supporte le grand récit mythique de la formation d'Ataúro et qui, avec ses variantes, est partagé par plusieurs groupes, à celle de l'histoire des conflits inter-groupes au sein de l'île avec pour marqueurs des sites remarquables, des fortifications, des sépultures, et encore à celle très localisée des territoires lignagers d'aujourd'hui, chacune de ces échelles mobilisant un interlocuteur légitimé pour donner des informations. Les récits, cosmogonique, mythique ou historique font état de personnages fondateurs qui parcourent le territoire et créent des alliances, de mondes souterrains qui mettent en relation des groupes différents, de récits de guerres, de récits de l'arrivée de la religion ou encore d'événements comme la cérémonie collective de l'arec qui mobilise toute l'île. L'ensemble dessine une géographie politique, sociale, historique et écologique des villages susceptibles d'appuyer des mesures de protection ou d'accès contrôlé à certains sites face au développement des infrastructures touristiques (Figure 23).

Figure 23 : Lîle d'Atauro et la transcription des informations de la tradition orale

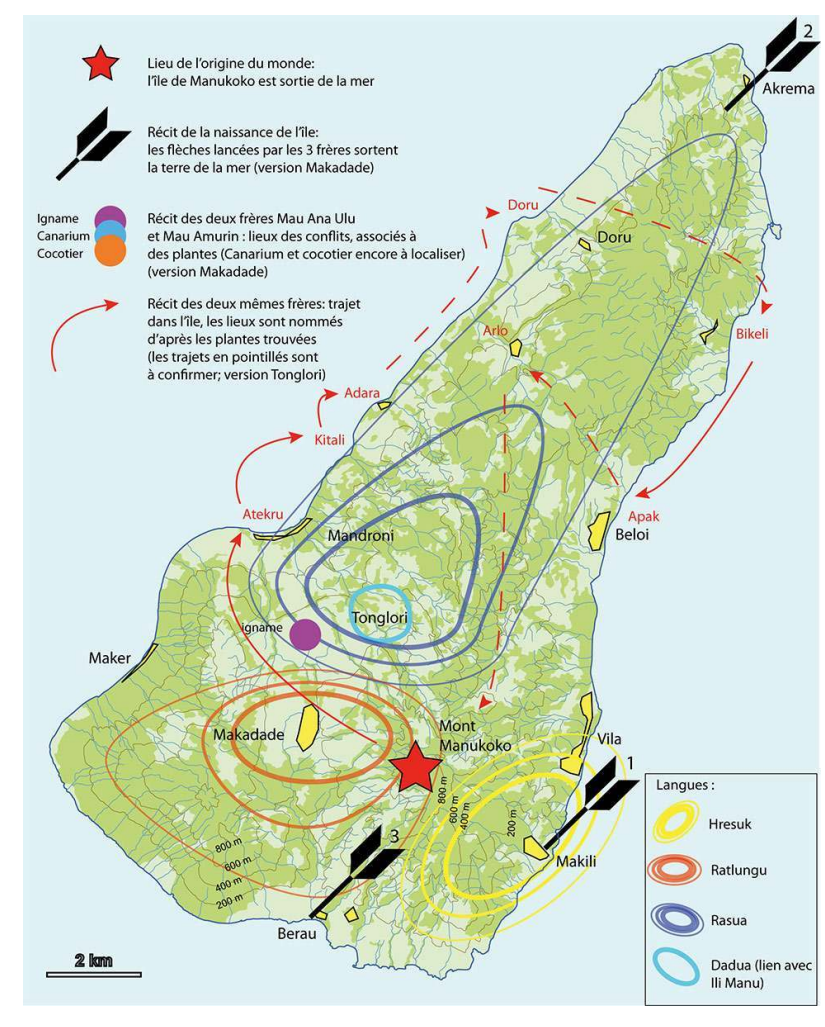

(c) L. Billault/D. Guillaud 


\section{Quelles restitutions? Quelle gouvernance locale des patrimoines et du territoire à Ataúro?}

De manière plus spécifique, les recherches concernent les trois villages de Arlo, Atekru et Makadade et des contacts ont été pris pour 2017 avec les responsables de Makili. Les matériaux recueillis ont trait à l'occupation ancienne de l'île avec les fouilles archéologiques, aux différents récits d'origine et à leur inscription territoriale, à la culture matérielle comme la pêche, la poterie, l'agriculture, la vannerie, le tissage de tais en fibre de Corypha utan (Figure 24) et les usages des ressources naturelles, thèmes qui éclairent également la richesse de l'histoire et des relations sociales sur l'île.

Figure 24 : Tissage de fibre de Corypha utan à Makadade

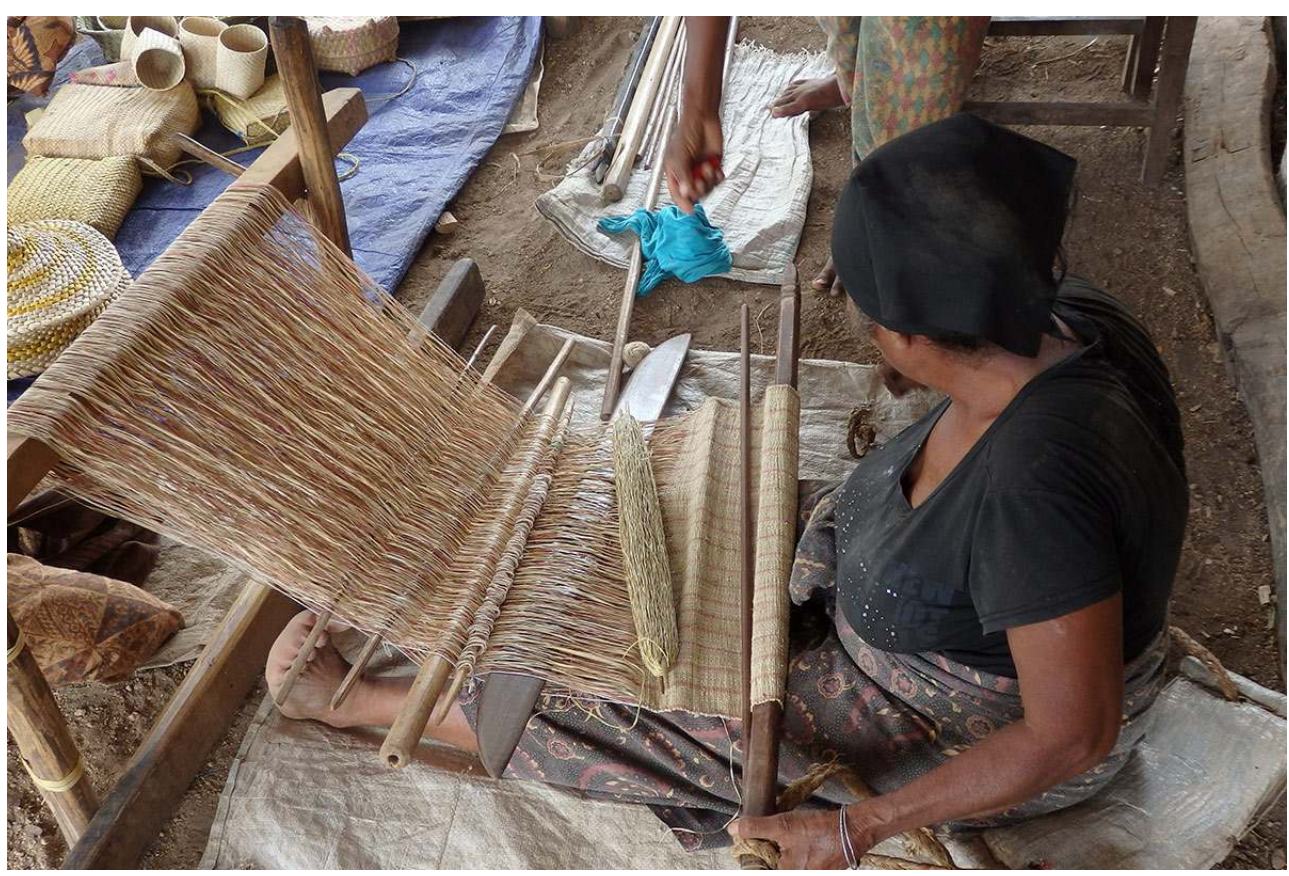

(c) L. Emperaire

50 Les premiers résultats se réfèrent au peuplement ancien. À Arlo, un abri a livré une séquence chronologique de céramique sur 3000 ans (Galipaud et al. 2016b). Ces résultats ont suscité une grande fierté de la part de la population du village, liée davantage à l'ancienneté révélée de l'occupation qu'à la diversité des cultures céramiques découvertes; le chef de suco était intéressé par une possible valorisation de cet abri. L'abri Lepukina, qui ne présente pas de caractéristique visuelle remarquable et dont les fouilles ont été remblayées, est vu localement sous un angle pragmatique. Situé sur le terrain d'un habitant du village, ce dernier souhaite une rentabilité financière, pour lui comme pour le village, mais que montrer d'une fouille refermée? Au départ, un panneau explicatif des découvertes a été proposé par les chercheurs puis, à ce panneau, a été adossée l'idée d'une vitrine retraçant l'histoire régionale de la céramique. Ces propositions émanent des chercheurs mais leurs principes sont validés par le responsable de village. 
51 En revanche, un atelier de revitalisation des savoirs liés à la poterie, organisé en partenariat entre l'ONG Empreza Di' ${ }^{20}{ }^{20}$ et le Secrétariat à la Culture, avec la participation de deux représentantes d'Arlo, a permis la réélaboration d'un savoir oublié depuis à peu près deux générations, du fait de l'arrivée des ustensiles de métal et plastique. Certains éléments de ce savoir (les sources de matières premières, la cuisson de la céramique) subsistaient mais d'autres semblaient oubliés. Aujourd'hui, la douzaine de potières du village reproduisent à l'identique des modes de faire en utilisant en particulier les mêmes sources de matériaux (argile ${ }^{21}$ et dégraissant) et produisent des petits pots à col (Figure 25) dont les seules variations sont données par les motifs décoratifs incisés. Ces pots sont vendus par Empreza Dia'k pour les touristes. Il y a ici reconstitution et perpétuation d'un patrimoine identifié à l'échelle générationnelle. En effet le dégraissant est prélevé toujours sur le même site, sur le territoire d'un village voisin, là où les potières âgées se souviennent avoir vu leur mère aller le rechercher, alors que nous leur avons signalé que d'autres sources plus proches seraient tout aussi acceptables ${ }^{22}$. Il y a une crainte de changer le moindre procédé dans ce geste technique hérité des ancêtres. Parallèlement, ce savoir est dissocié de l'histoire sur le long terme mise au jour sur le site archéologique, où des formes et qualités différentes de poterie ont été découvertes. La reconstitution graphique d'un de ces modèles anciens, qui aurait pu être une source d'inspiration pour les potières, n'a pas eu beaucoup d'écho ${ }^{23}$.

Figure 25 : Confection de poterie, Arlo

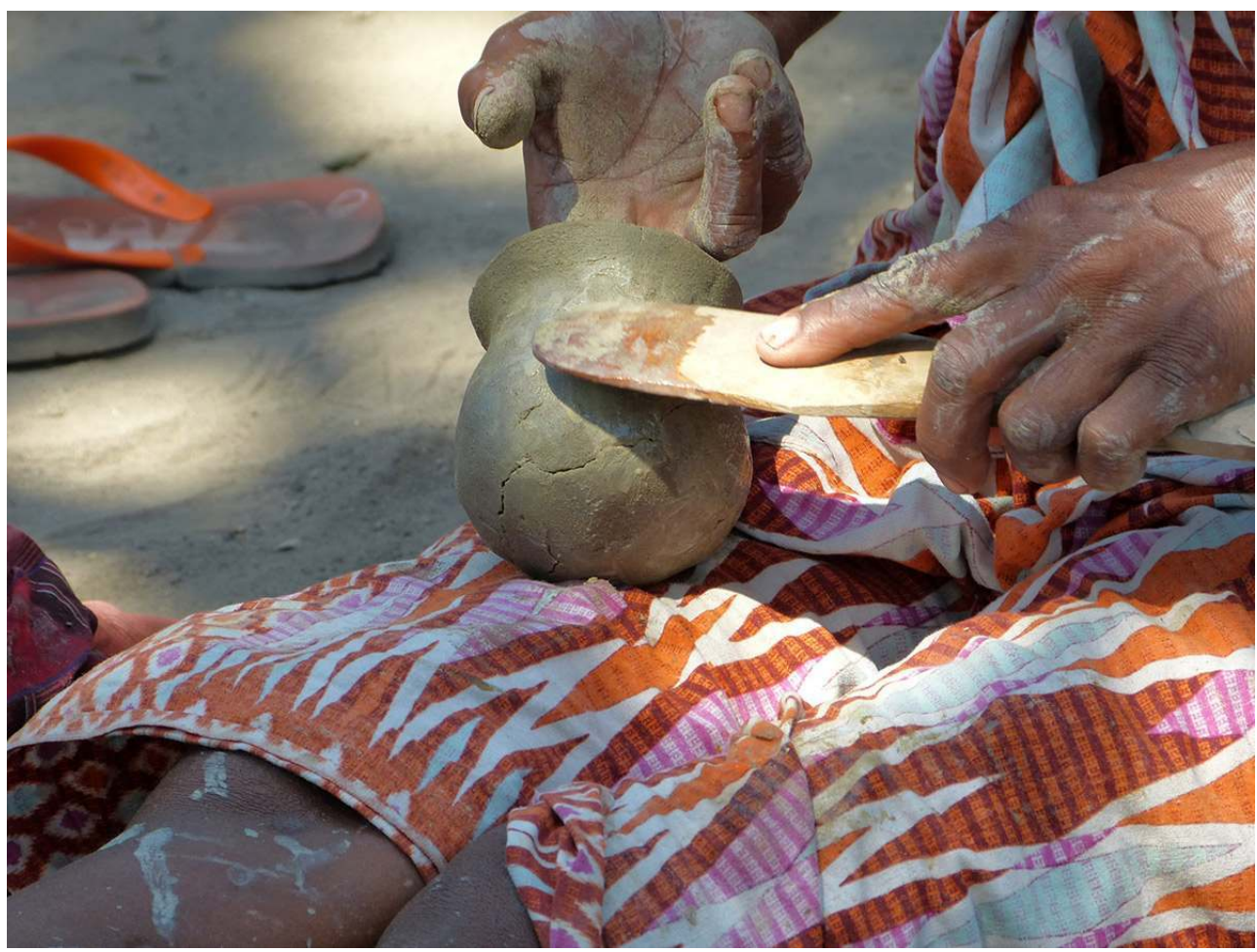

(c) D.Guillaud

52 À Atekru, sur le littoral ouest, la fouille d'un abri sous roche orné, Aleti Tunu Bibi (Figure 26), a permis l'établissement d'une chronologie sur 18000 ans (Galipaud et al. 2016a, 2016b). Un panneau informatif en trois langues (tetun, anglais, portugais) sur les peintures et les fouilles de l'abri sous roche a été conçu par les chercheurs avec l'accord du chef de village. Deux posters en toile bâchée ont aussi été imprimés à l'intention de 
l'école du village et le panneau doit être prochainement mis en place avec une inauguration officielle. En attendant, le secrétariat d'État à la culture prévoit de construire, à la grande satisfaction des habitants, un chemin cimenté avec des abris réguliers sur tout le trajet jusqu'à la grotte. Les habitants du village en espèrent un droit de passage versé par les touristes.

Figuer 26 : Peinture rupestres de l'abri Lepu Kina, Atekru

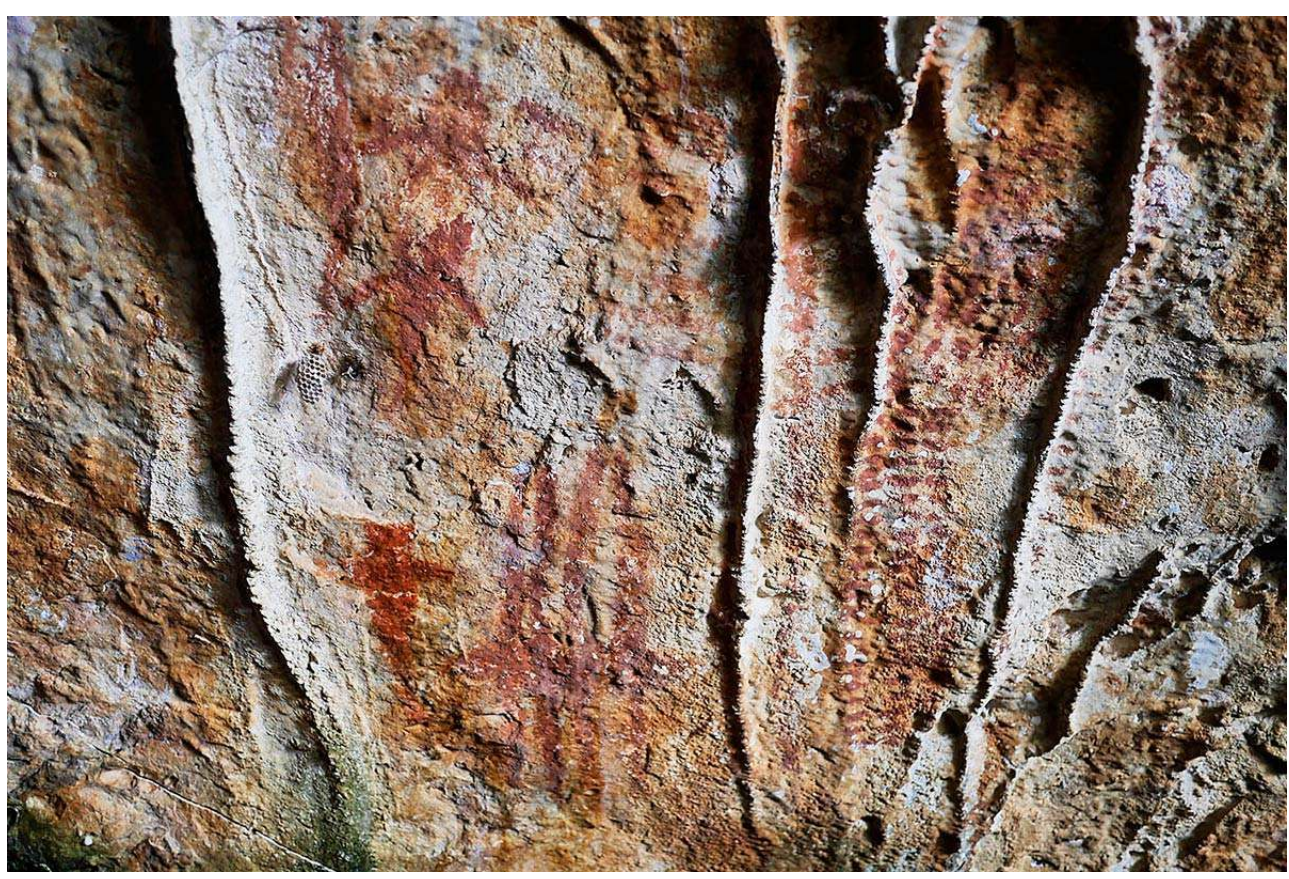

(C) D. Guillaud

53 Une autre configuration de valorisation des patrimoines se dessine à Makadade avec la médiation d'interlocuteurs qui se positionnent sur le créneau ouvert par la présence de nouveaux acteurs sur l'île, chercheurs, experts envoyés pour l'établissement du Plano de ordenamento territorial ou touristes, ainsi que par les activités de l'ONG Empreza Dia'k, et les cours d'anglais donnés par Seeds of Life en 2016. Leur connaissance de l'anglais, de l'indonésien et des langues locales en font des guides scientifiques, susceptibles de mobiliser d'autres spécialistes de tel ou tel thème dans le village, ou des guides touristiques (Figure 27). Cette brève énumération montre bien comment chaque type d'acteurs est susceptible de porter son propre discours sur le développement: depuis celui des femmes, peu visible si ce n'est à travers les ONG, à celui de ces nouveaux médiateurs. 
Figure 27 : Discussion autour d'une carte, Atekru

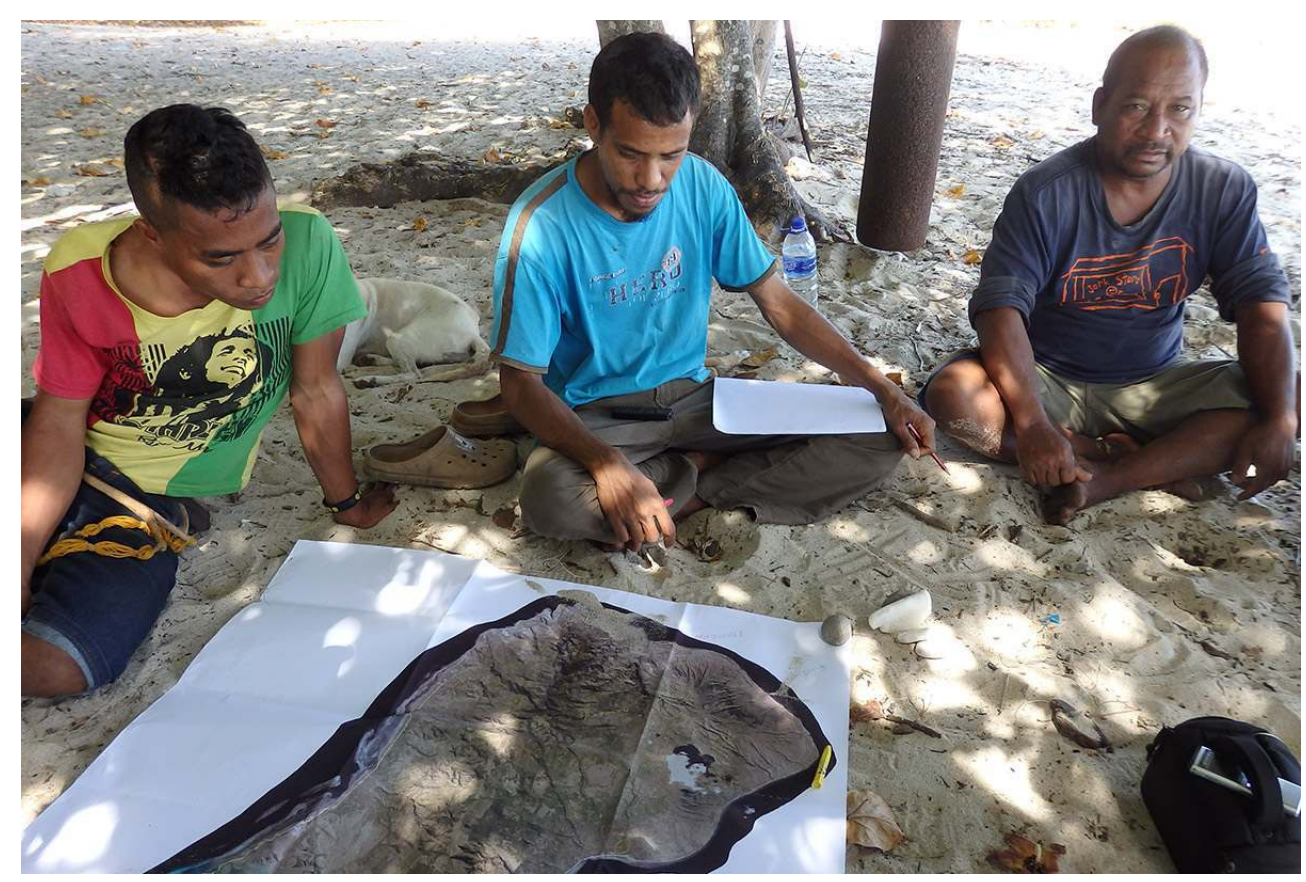

(c) L. Emperaire

\section{Conclusion}

Les recherches, même non encore abouties, ouvrent déjà à plusieurs conclusions et limites de l'approche participative, et, par là, de l'outil cartographie participative. La première est que se révèle une multiplicité de statuts et de détenteurs de savoirs sur les patrimoines dont l'expression générique "population locale » ne rend pas compte. Par ailleurs, si le recueil de ce qui constitue une culture mise à mal pendant 25 ans est parfaitement compris par les populations, notre démarche laisse de côté certains acteurs locaux. En effet, dans ces sociétés très hiérarchisées, le savoir n'est pas donné à tous, il est fractionné : chaque maison noble a son savoir, chaque lieu son responsable, et certaines connaissances aux mains des anciens tracent ici les limites du collaboratif. Un parcours du terrain avec les femmes donne des résultats différents : elles indiquent les puits sacrés où elles puisent l'eau pour les cérémonies, les sites où elles vont collecter de la glaise pour leurs poteries, l'espace des champs, ou celui de la collecte des plantes pour les teintures des tissus. Il en ressort ainsi des lieux masculins et des lieux féminins, des patrimoines nobles, et d'autres profanes, des sacralités générales et d'autres plus ordinaires, dont la cartographie peine à rendre compte.

Les défis de la recherche participative en cours, avec sa composante cartographique, sont d'appuyer la reconnaissance des droits locaux sur leurs patrimoines et d'en imaginer des formes de visibilité qui à la fois assurent leur dynamisme et permettent un dialogue entre détenteurs et acteurs politiques, économiques et scientifiques. C'est là une seconde difficulté, car nous avons essayé de rencontrer les responsables du projet pétrolier pour discuter des résultats dans la région de Suai, mais la rencontre n'a pas été possible. Il ne faut pas non plus sous-estimer la capacité de nos recherches de révéler certains conflits, en particulier concernant l'appropriation de la terre. Notons ainsi que le projet Tasi Mane 
et le projet d'aménagement d'Ataúro ont été les premiers événements requérant la mise en place d'un cadastre dans chacune des régions. Jusque-là, l'ensemble du foncier était régi par un accord coutumier portant sur les limites entre les groupes, jadis fixées par les ancêtres et sujettes à des interdictions; toute modification les concernant requérait de longues discussions entre les conseils d'anciens des groupes impliqués et les changements ne pouvaient se faire qu'au prix d'importantes cérémonies. À Ataúro, des murs de pierre matérialisent les limites entre les clans et c'est une offense coutumière grave que de déplacer les grosses pierres de la base de ces murs (Figure 28). La mise en place d'un cadastre foncier, à l'occasion des grands aménagements cités, a été un révélateur et, plus encore, un catalyseur des tensions entre les usagers, puisqu'il a rendu visible l'enchevêtrement et la superposition de plusieurs types de droits au sein du système coutumier. Les incompatibilités des règles de gestion de l'État et de la coutume ont été ainsi révélées. Plus précisément, le passage d'un système oral à un système de titres de propriété équivalait à passer d'une tenure en "commons" à une propriété privée. Comme c'est souvent le cas au Timor-Leste, la tenure en communs est elle-même particulièrement complexe, ce qui ne pose pas de problème particulier dans un système coutumier régulé au cas par cas, au fur et à mesure des besoins et des usages. Les terres relèvent en effet des maisons originelles qui, en se scindant pour créer de nouvelles maisons et en accueillir d'autres, entrant dans le système des alliances matrimoniales, ont généré des droits subordonnés à un théorique "droit initial », mais où la légitimité d'une maison plus récente sur les terres qu'elle s'est vue attribuer n'a pas de raison d'être remise en cause. De plus, des droits d'usage à des degrés divers de terres prêtées, souvent depuis des générations, rendent inextricable la question des droits relevant des maisons détentrices des droits initiaux et des maisons exploitantes. Les litiges fonciers traditionnels font intervenir les spécialistes d'une «mémoire des partages» qui reconstituent, au cours de longues sessions, l'enchevêtrement séculaire des appropriations et des usages. Du fait de cet enchevêtrement, le plus visible en matière de droits fonciers est le droit d'usage actuel de la terre, qui tend à guider les employés du cadastre pour leurs relevés et attributions, mais qui suscite souvent des contestations ou ravive d'anciennes querelles (voir notamment Le Roy 2011). Le plus récent de ces avatars territoriaux est le cadastre officiel qui matérialise les frontières et fige le territoire, en évacuant toute possibilité de négociation entre les parties prenantes. C'est au prix d'une connaissance fine des groupes locaux et de leurs enjeux que ces conflits peuvent être évités, et la cartographie participative peut s'avérer un outil partagé de négociation territoriale. Les lieux et les géosymboles en eux-mêmes ne font pas l'objet de contestation, en revanche les récits qui les animent posent la question de la légitimité de ceux qui les énoncent. L'archéologie joue ici un rôle fédérateur en proposant aux populations locales les évidences matérielles d'une histoire commune valorisante dont l'ancienneté assure l'acceptation par tous.

Enfin, les modalités de l'accès aux informations sont aussi très différentes entre les deux contextes présentés. Cela confirme l'importance de travailler à partir des représentations des populations locales, aucune catégorie a priori ne pouvant être valable pour tous les contextes. D'abord, cette approche renouvelle complètement le regard scientifique sur le patrimoine et aboutit à des visions patrimoniales originales, sans rapport avec les catégories institutionnelles. Dans cet aspect du participatif réside sans doute une possibilité de renouveler aussi une approche scientifique en sciences humaines et sociales qui a permis de rassembler des informations considérables sur les lignes de force de la société. 


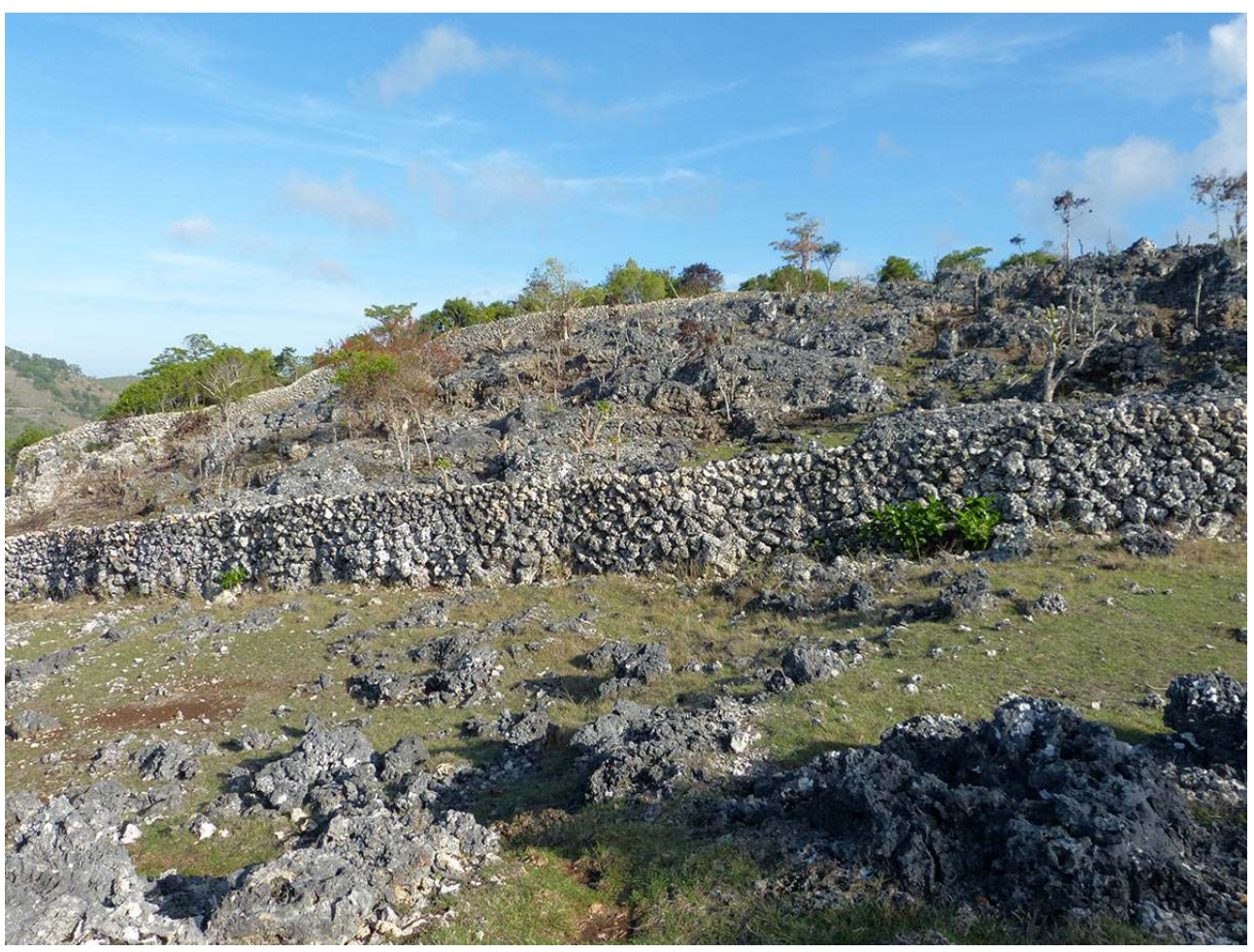

(c) D. Guillaud

Ensuite, les solutions doivent être sur mesure pour les populations locales. Faute d'une demande locale structurée dans un contexte où les communautés sont très fractionnées et les visions très institutionnelles, les objectifs ont été proposés par les chercheurs puis infléchis ou adaptés par les populations locales, définissant ce qu'on pourrait nommer un top-down-up. La situation d'Ataúro peut dans une certaine mesure être comparée au contexte amazonien dans lequel a émergé L'encyclopédie de la forêt, le haut-Juruá : pratiques et connaissances des populations (Carneiro da Cunha \& Almeida 2002): des recherches interdisciplinaires, reliant anthropologie, écologie, botanique, zoologie etc.; une période marquée par un projet national de valorisation économique (substitution de la forêt par des pâturages) des espaces de vie de populations traditionnelles ; une méconnaissance des savoirs et pratiques de ces populations (dans ce cas seringueiros et populations amérindiennes) sur les espaces qui constituent leur cadre de vie ; des formes de recherche qui mêlaient recherche "traditionnelle » (avec une production universitaire de thèses et de masters) et collaborative. Il en a résulté une publication subventionnée notamment par le ministère brésilien de l'Environnement, qui atteste de la richesse et de la vitalité des savoirs locaux, au-delà de leur seule perspective utilitaire. Ce type d'encyclopédie, qui serait aussi en ligne, est une option possible pour l'île.

Une autre demande émane aujourd'hui de la communauté de Kamanasa à Suai: les lianain voudraient que les résultats des recherches, cartes et récits, soient réunis en un ouvrage placé dans une boîte enveloppée de tissu traditionnel, laquelle devra être officiellement remise à chacune des maisons nobles; elle sera ensuite disposée dans le «trésor» de chacune d'elles. Outre qu'elle confirme le souhait de ces populations de voir, pour des raisons qu'on imagine diverses, leur culture documentée, cette demande 
souligne la charge symbolique des données qui ont ainsi été livrées aux chercheurs, et qu'on ne peut considérer à la légère.

\section{BIBLIOGRAPHIE}

Barraud C. 2015 - Parenté, Alliance, Maisons Dans l'Est Insulindien : L'école Néerlandaise et Sa Postérité Critique. Archipel $90: 217-44$.

Bicca A. 2011 - A diferença entre os iguais, PhD, Universidade Federal do Rio Grande do Sul, Dpt, Anthropologie sociale, Porto Alegre.

Boeke J.H. 1953 - Economics and Economic Policy of Dual Societies as exemplified by Indonesia. New York, Institute of Pacific Relations.

Bonnemaison J. 1981 - Voyage autour du territoire. L'Espace géographique 10 (4) : 249-262.

Bovensiepen J. \& Delgado R.F. 2016 - Transformations of the Sacred in East Timor. Comparative Studies in Society and History 58 (3) : 664-693.

Cabasset-Semedo C. \& Durand F. 2009 - East-Timor. How to Build a New Nation in Southeast Asia in the 21st Century? Carnet de l'Irasec / Occasional Paper n 9 , Bangkok.

Cabasset-Semedo C. 2007 - Initiatives locales, politique nationale et organisations internationales : les enjeux du tourisme au Timor oriental. Hérodote 127 : 178-189.

Carneiro da Cunha M. \& Almeida M.W.B. de 2002 - Enciclopédia da Floresta, o Alto Juruá: práticas e conhecimentos das populações. São Paulo, Ed. Companhia das Letras.

Chopra J. 2002 - Building State Failure in East Timor. Development and Change 33 (5) : 979-1000.

Cormier-Salem M.-C. \& Guillaud D. 2016 - Des mémoires récupérées aux patrimines survalorisés : pour une démarche réflexive sur les acteurs du patrimoine. In Guillaud D., Juhé-Beaulaton D., Cormier-Salem M.-C. \& Girault Y. (Ed.) Ambivalences patrimoniales au Sud - Mise en scène et jeux d'acteurs. Paris, IRD-Karthala : 257-271.

Cryan M. 2015 - Dispossession and Impoverishment in Timor-Leste: The Potential Impacts of the Suai Supply Base. SSGM Discussion Paper, ANU.

Direksaun Jeral de Estatistika 2015 - Statistics Timor Leste, census publication 2015. http:// www.statistics.gov.tl/category/publications/census-publications/

Durand F. 2002 - Timor Lorosa'e, Pays Au Carrefour de l'Asie et Du Pacifique; Un Atlas Géo-Historique. Champ-sur-Marne, Bangkok, Presses Universitaires de Marne-la-Vallée, IRASEC.

Fox J.J. 2006 - Genealogy and Topogeny: Towards an Ethnography of Rotinese Ritual Place Names. The Poetic Power of Place: Comparative Perspectives on Austronesian Ideas of Locality : 89-100.

Francillon G. 1967 - Some Matriarchic Aspects of the Social. Structure of the Southern Tetun of Middle Timor. PhD Thesis, Canberra: ANU, 478 p.

Friedberg C. 1971 - L'agriculture Des Bunaq de Timor et Les Conditions D'un Équilibre Avec Le Milieu. Journal d'Agriculture Tropicale et de Botanique Appliquée 12 : 481-532. 
Friedberg C. 2014 - Protéger Les Humains et Les Non- Humains. Revue d'Ethnoécologie 6 : 0-16.

Galipaud J.C., Kinaston R. \& Guillaud D. 2016a - Aleti Tunu Bibi : Contextualizing a New Rock Art Site in East Timor and the Wider Asia-Pacific Region. Asian Perspectives, 55 (2):128-147.

Galipaud J.C. \& Guillaud D. 2016b - Identities, territories and agricultural practices: some landmarks for the preservation of local communities Heritage in East Timor. Four years of research and training in the field of Archaeology in Timor Leste, a synthesis. PALOC special publication, IRD/MNHN, Dili, $170 \mathrm{p}$.

Guillaud D. 2015 - Le vivrier et le sacré. Systèmes agricoles, rituels et territoires dans l'Est indonésien et à Timor-Leste. Archipel 90 : 245-274.

Hicks D. 1996 - Making the King Divine: A Case Study in Ritual Regicide from Timor. The Journal of the Royal Anthropological Institute 2 (4) : 611-24.

Kehi B. \& Palmer L. 2012 - Hamatak Halirin: The Cosmological and Socio-Ecological Roles of Water in Koba Lima, Timor. Bijdragen Tot de Taal-, Land-En Volkenkunde 168 (4) : 445-71.

La'o Hamutuk 2014 - ZEMS https://www.laohamutuk.org/econ/Oecussi/ZEESMIndex.html Le Roy É. 2011 - La terre de l'autre. Une anthropologie des régimes d'appropriation foncière. Paris, LGDJ Lextenso, $441 \mathrm{p}$.

Ministry of Finances 2011 - Timor-Leste Household Income and Expenditure Survey.

Ministry of Finances 2015 - https://www.mof.gov.tl/about-the-ministry/statistics-indicators/ sensus-fo-fila-fali/download-suco-reports/?lang=en - consulté le 12 décembre 2016.

Scheiner C. 2015 - Can the Petroleum Fund Exorcise the Resource Curse from Timor-Leste? In : Ingram S., Kent L. \& McWilliam A. (Ed.) A New Era? Timor-Leste after the UN, Canberra, ANU Press : 73-101.

Therik T. 2004 - Wehali, the Female Land. Traditions of a Timorese ritual centre. Canberra : ANU. (Monographs in Anthropology Series).

\section{NOTES}

\section{Dans l'UMR PALOC}

2. Pour une revue synthétique de cette notion complexe, voir Barraud 2015.

3. L'histoire montre que depuis le $\mathrm{XVII}^{\mathrm{e}}$ siècle au moins on assiste au développement des plantes américaines, maïs et manioc prenant le pas sur millet et sorgho. Cet essor a probablement enclenché une transformation importante des paysages avec l'extension des abattis-brûlis. Les Portugais, en imposant la culture du café dans le milieu du XIX ${ }^{\mathrm{e}}$ siècle dans les hautes terres de l'ouest, la culture du coton et celle du riz irrigué dans les années soixante dans les basses-terres alluviales (Durand 2002 : 110), ont poussé à accroître ces défrichements. Au début du $\mathrm{xx}^{\mathrm{e}}$ siècle, l'impôt en maïs a accru encore ce développement des surfaces, et cette contrainte a modifié la répartition des populations qui ont migré pour trouver de nouvelles terres, et sont pour certaines descendues dans les plaines.

4. L'armée indonésienne a notamment pratiqué les brûlis pour débusquer la résistance qui s'y réfugiait. Les cultures nouvelles requérant d'amples surfaces, les pratiques de chasse utilisant le feu, les coupes de bois pour les besoins domestiques, et aussi le déplacement de populations qui ne connaissaient pas les interdits traditionnels des aires où on les installait ont tous joué un rôle dans l'état très dégradé d'une grande partie des milieux du Timor Leste.

5. https://www.laohamutuk.org/OilWeb/Chronology.htm 
6. Qui correspond au départ de la force des Nations-Unies.

7. Le revenu moyen est de l'ordre de 634 \$/an en ville, 292 \$ à la campagne (Ministry of Finance 2011 : 7).

8. Quelques rares administrateurs et décideurs, les plus âgés, ont été formés par les Portugais. Parmi les plus jeunes, certains ont été formés à l'étranger, souvent en Australie, mais préfèrent quand ils ont des diplômes s'employer dans les ONG ou la coopération internationale où salaires sont plus élevés que dans le gouvernement.

9. Le SEAC relève en 2017 du Ministère du Tourisme alors qu'auparavant il était rattaché au ministère de l'Éducation. Ces services de la culture n'ont pas de lien avec les instances chargées de l'environnement, témoignant d'une vision très déconnectée des relations entre nature et culture.

10. Ces deux villages sont constitués de plusieurs hameaux (aldeia) : Holbelis (1532 habitants) comprend Mukbelis, Roek, Bonuk 1 et 2. Kamanasa (3 681 habitants) comprend Fatisin et Sanfuk, touchés par le projet, mais aussi Maneikin et Ai-Lo'ok Laran (Direksaun Jeral de Estatistika 2015).

11. www.timoraid.org

12. C'était un type de réalisation qu'ils venaient d'éprouver avec les textiles : cf expositions de Suai/Covalima Hatene ami-nia moris | Know our World, $1^{\text {er }}-9$ avril 2015 The Gallery, St Kilda Town Hall, Melbourne, Australia, et 10 juillet 2015 aux Archives de la Résistance timoraise, Dili, cette dernière à laquelle nous avons contribué.

13. Les villages touchés par le projet Tasi Mane relèvent de deux composantes linguistiques, le tetun terik et le bunaq, relevant de deux familles distinctes (austronésienne et nonaustronésienne).

14. Holbelis, village bunaq actuel, a hérité du banian central du village antérieur des Tetun chassés par les Portugais (voir supra). Les Bunaq n'ont pas d'arbre central dans leurs villages, mais ce banian, qui est en périphérie des habitats, n'en conserve pas moins à leurs yeux un caractère sacré et est hautement respecté. Comme il doit être abattu pour l'élargissement de la piste d'aviation, les habitants bunaq ont décidé de mettre en place une cérémonie pour couper une bouture et la replanter de l'autre côté du village, de façon à préserver la sacralité de l'arbre. Les sociétés bunaq et tetun conçoivent la possibilité de déplacer des sites sacrés ou d'en constituer des répliques (des sortes de " portails ») plus commodes d'accès.

15. Pour le village de Kamanasa, ils ont été pris en charge par la suite par Brunna Crespi, dans le cadre de sa thèse sur les impacts du projet pétrolier sur l'organisation coutumière dans la région de Suai.

16. Francillon (1967 : 34-35) signale que du côté néerlandais du Timor, les nai [lianain] ont été les premiers chargés des relations avec l'administration coloniale.

17. L'île est une mosaïque linguistique. Le rasua est principalement parlé à Beloi et Bikeli, le raklungu à Makadade et le hresuk à Makili, ces trois langues seraient trois variantes d'une même langue du tronc austronésien (Bicca 2011). Le dadua (ou galoli), qui fait partie d'un autre groupe de langues austronésiennes, est parlé à Tonglory et à Bikeli (Min. Finances 2015).

18. http://timor-leste.gov.tl/?p=14450\&lang=en\&lang=en

19. Projet TIMLEST financé par le Ministère de la Culture et de la Communication, appel Pratiques scientifiques et techniques au regard des politiques culturelles.

20. http://empreza-diak.com/

21. La seule source de «bonne argile " pour la poterie dans l'île serait à Arlo. D'autres villages cependant (Makadade) affirment avoir des sources d'argile équivalente, ce qui peut signaler les débuts d'une concurrence.

22. Le village voisin d'où provient le dégraissant a indiqué qu'il ferait payer les prélèvements dès la mise en place des titres fonciers.

23. Peut-être du fait que seuls des hommes ont participé à la fouille et ont pu voir l'origine des tessons qui ont permis la reconstitution. 


\section{RÉSUMÉS}

Timor-Leste, pays jeune et fortement multiculturel, mise pour son avenir sur le développement d'infrastructures lourdes. Ses politiques culturelles sont également en construction; pour l'instant, elles procèdent par la valorisation d'objets convenus, emblématiques d'une diversité culturelle pensée à l'échelle nationale. Mais les patrimoines forgés, transmis, actualisés par les populations locales sont peu pris en compte. A partir de deux situations, celle du littoral sud avec un projet pétrolier et celle d'une petite île au nord de la capitale visée par le tourisme, nous proposons une réflexion sur la nature des patrimoines locaux (espaces, biodiversité, objets sacrés, lieux sacrés, récits d'origine ...) et sur la façon dont ils intègrent, depuis toujours, une certaine modernité. Les objectifs du groupe de recherche sont de construire un processus collaboratif d'identification et de mise en valeur de ces patrimoines, en prenant en compte la diversité des acteurs concernés. Ils visent aussi à analyser les atouts et limites de telles démarches participatives qui, tout en favorisant le dialogue entre recherche, populations et politiques publiques, sont encore loin d'être à même de rendre compte de la multiplicité des statuts des objets patrimoniaux et des détenteurs de savoirs, et peuvent révéler des situations de tension dans le domaine foncier. Notre analyse montre que la cartographie participative ne peut être qu'un instrument parmi d'autres dans les méthodologies collaboratives.

Timor-Leste, a young country with a rich cultural diversity, is betting for its future on the development of heavy infrastructure. Its cultural policies are also under construction; presently, they focus on the promotion of conventional objects that are emblematic of the cultural diversity perceived at a national level. However, local populations have their own heritage that they have created, transmitted and updated, and which is hardly ever taken into account. We propose a reflection on the nature of this local heritage (territory, biodiversity, sacred objects, sacred places, narratives of origin, etc.), and on the way it has always incorporated a certain modernity. This reflection is derived from two field studies: the south coast with an oil project and a small island off the northern coast, targeted by tourism. The objectives of the research group are to build a collaborative process in order to identify and develop this heritage, while considering the diversity of the actors involved. They also aim at analyzing the strengths and limitations of such participatory approaches; although favoring the dialogue between research, populations and public policies, these approaches do not always account for the diversity of heritage objects and of holders of knowledge, and may reveal situations of tension in the land system. Our analysis shows that participatory mapping can only be one instrument among others in collaborative methodologies.

\section{INDEX}

Index géographique : Timor-Leste

Mots-clés : patrimoine, approche participative, représentations, populations locales, conservation, cartographie participative, foncier, territoire, rituels, restitution, pétrole, tourisme Keywords : heritage, participatory approach, representations, local populations, conservation, participative cartography, land system, territory, rituals, restitution, oil, tourism, East Timor 


\section{AUTEURS}

\section{DOMINIQUE GUILLAUD}

Directeur de recherche IRD, UMR Paloc, Sorbonne-Universités, Paris

\section{LAURE EMPERAIRE}

Directeur de recherche IRD, UMR Paloc, Sorbonne-Universités, Paris

\section{BRUNNA CRESPI}

Doctorante, UMR Paloc, Sorbonne-Universités, Paris

ROSALIA SOARES

Chercheur ONG Timor Aid, Dili

\section{AMANDINE PEQUIGNOT}

Maître de conférences du Muséum, UMR Paloc, Sorbonne-Universités, Paris

\section{JEAN-CHRISTOPHE GALIPAUD}

Chargé de recherche IRD, UMR Paloc, Sorbonne-Universités, Paris 